\title{
pH-switchable nanozyme cascade catalysis: a strategy for spatial-temporal modulation of pathological wound microenvironment to rescue stalled healing in diabetic ulcer
}

Xuancheng Du ${ }^{1 \dagger}$, Bingqing Jia ${ }^{1 \dagger}$, Weijie Wang ${ }^{1}$, Chengmei Zhang ${ }^{2}$, Xiangdong Liu', Yuanyuan Qu', Mingwen Zhao ${ }^{1}$, Weifeng $\mathrm{Li}^{1}$, Yanmei Yang ${ }^{3^{*}}$ and Yong-Qiang $\mathrm{Li}^{1,4^{*}}$ (D)

\begin{abstract}
The management of diabetic ulcer (DU) to rescue stalled wound healing remains a paramount clinical challenge due to the spatially and temporally coupled pathological wound microenvironment that features hyperglycemia, biofilm infection, hypoxia and excessive oxidative stress. Here we present a pH-switchable nanozyme cascade catalysis (PNCC) strategy for spatial-temporal modulation of pathological wound microenvironment to rescue stalled healing in DU. The PNCC is demonstrated by employing the nanozyme of clinically approved iron oxide nanoparticles coated with a shell of glucose oxidase $\left(\mathrm{Fe}_{3} \mathrm{O}_{4}-\mathrm{GOx}\right)$. The $\mathrm{Fe}_{3} \mathrm{O}_{4}-\mathrm{GOx}$ possesses intrinsic glucose oxidase ( $\mathrm{GOx}$ ), catalase (CAT) and peroxidase (POD)-like activities, and can catalyze pH-switchable glucose-initiated GOx/POD and GOx/ CAT cascade reaction in acidic and neutral environment, respectively. Specifically, the GOx/POD cascade reaction generating consecutive fluxes of toxic hydroxyl radical spatially targets the acidic biofilm ( $\mathrm{pH} \sim 5.5$ ), and eradicates biofilm to shorten the inflammatory phase and initiate normal wound healing processes. Furthermore, the GOx/CAT cascade reaction producing consecutive fluxes of oxygen spatially targets the neutral wound tissue, and accelerates the proliferation and remodeling phases of wound healing by addressing the issues of hyperglycemia, hypoxia, and excessive oxidative stress. The shortened inflammatory phase temporally coupled with accelerated proliferation and remodeling phases significantly speed up the normal orchestrated wound-healing cascades. Remarkably, this $\mathrm{Fe}_{3} \mathrm{O}_{4}$ - $\mathrm{GO}$-instructed spatial-temporal remodeling of DU microenvironment enables complete re-epithelialization of biofilm-infected wound in diabetic mice within 15 days while minimizing toxicity to normal tissues, exerting great transformation potential in clinical DU management. The proposed PNCC concept offers a new perspective for complex pathological microenvironment remodeling, and may provide a powerful modality for the treatment of microenvironment-associated diseases.
\end{abstract}

\footnotetext{
*Correspondence: yym@sdnu.edu.cn; yqli@sdu.edu.cn

${ }^{\dagger}$ Xuancheng Du and Bingqing Jia contributed equally to this work

1 Institute of Advanced Interdisciplinary Science, School of Physics,

Shandong University, Jinan 250100, China

${ }^{3}$ College of Chemistry, Chemical Engineering and Materials Science,

Collaborative Innovation Center of Functionalized Probes for Chemical

Imaging in Universities of Shandong, Key Laboratory of Molecular

and Nano Probes, Ministry of Education, Shandong Normal University,

Jinan 250014, China

Full list of author information is available at the end of the article
}

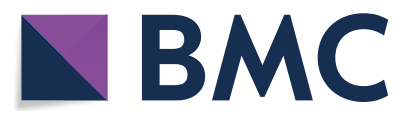

(c) The Author(s) 2021. Open Access This article is licensed under a Creative Commons Attribution 4.0 International License, which permits use, sharing, adaptation, distribution and reproduction in any medium or format, as long as you give appropriate credit to the original author(s) and the source, provide a link to the Creative Commons licence, and indicate if changes were made. The images or other third party material in this article are included in the article's Creative Commons licence, unless indicated otherwise in a credit line to the material. If material is not included in the article's Creative Commons licence and your intended use is not permitted by statutory regulation or exceeds the permitted use, you will need to obtain permission directly from the copyright holder. To view a copy of this licence, visit http://creativecommons.org/licenses/by/4.0/. The Creative Commons Public Domain Dedication waiver (http://creativeco mmons.org/publicdomain/zero/1.0/) applies to the data made available in this article, unless otherwise stated in a credit line to the data. 
Keywords: Biofilm eradication, Cascade catalysis, Diabetic ulcer, Nanozyme, Pathological microenvironment modulation

\section{Graphical Abstract}

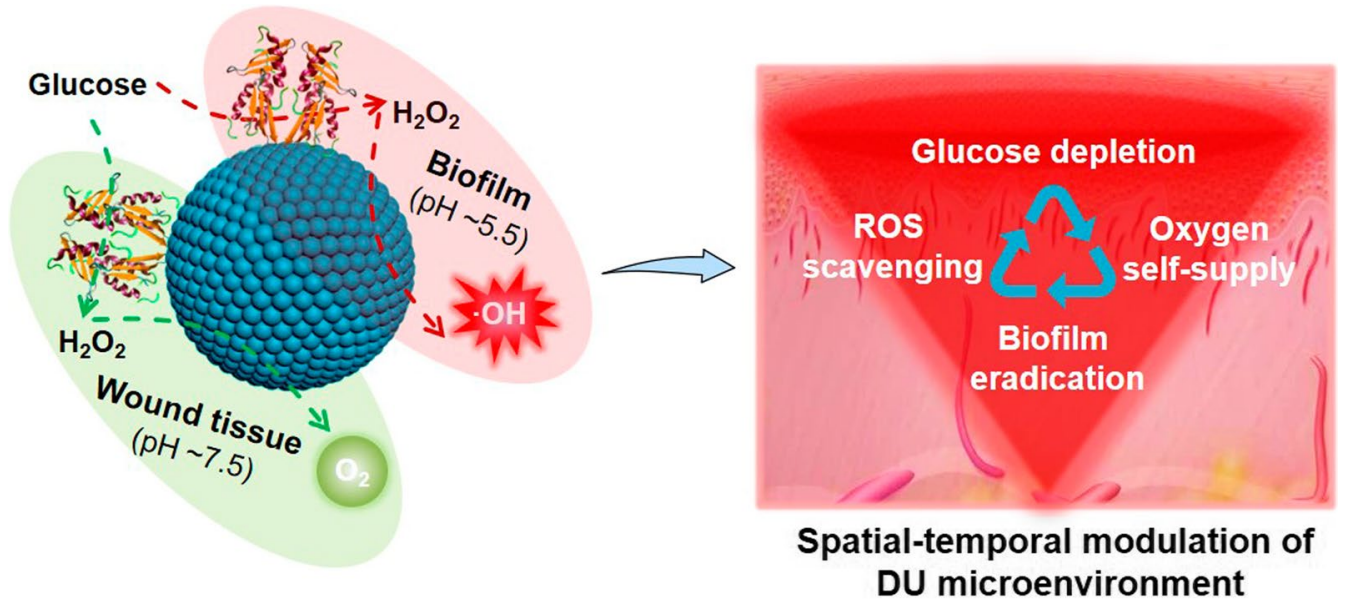

\section{Introduction}

Diabetes affecting 451 million people has become a global epidemic, and poses mounting public health concerns due to its clinical complications [1]. Diabetic ulcer (DU) characterized by extremely slow or even stagnant wound-healing cascades (hemostasis, inflammation, proliferation and remodeling) that usually form on the feet and legs, is an intractable complication of diabetes [2]. Despite continuous improvements in tissue engineering and regeneration, the treatment of DU remains a grand clinical challenge, resulting in high rate of limb amputations and causing an enormous medical and financial burden [3, 4]. The spatially and temporally coupled pathological wound microenvironment that features hyperglycemia, hypoxia, biofilm infection and excessive oxidative stress, is the culprit for the dilemma of DU treatment [5]. Specifically, the spatially coexisted biofilm (bacterial community wrapped by self-produced extracellular polymeric substances) and wound tissue have completely different pathological characteristics, setting a myriad of stumbling blocks and greatly enhancing the difficulty of DU $[6,7]$. Meanwhile, the prolonged inflammatory phase resulted from biofilm infection is temporally coupled with the stagnant proliferation and remodeling phases attributed to the synergy of hyperglycemia, hypoxia, and excessive oxidative stress in DU [810], causing non-healable wounds. Therefore, reshaping the spatially and temporally coupled pathological wound microenvironment to rescue stalled healing is critical for the treatment of DU.

By individually targeting the issues of hyperglycemia, hypoxia, bacterial infection and excessive oxidative stress, sophisticated strategies for pathological wound microenvironment remodeling have been presented including glucose regulation [11], local oxygen delivery [12, 13], photothermal and photodynamic antimicrobial therapy $[14,15]$, and ROS scavenging [16-18]. A variety of effective multifunctional biomaterials such as hydrogels and electrospun polymer micro/nanofibers, have been prepared based on these strategies to alleviate pathological microenvironment and help restore the healing cascades in chronic wound [19-22]. However, their therapeutic effect on DU is not ideal due to the mutual influence and synergy of hyperglycemia, hypoxia, biofilm infection, and excessive oxidative stress in diabetic wound [5]. To simultaneously address all these DU-related issues, recently integrated hydrogel systems have been reported by assembling function modules of glucose depletion, oxygen delivery, bacterial biofilm elimination and ROS removal into one hydrogel, notably accelerating the healing of diabetic wound $[6,23,24]$. However, these function modules of the integrated hydrogels are independent of each other and lack the spatial-temporal synergy mechanism to achieve better wound healing effects. Moreover, this all-in-one assembly strategy makes the composition of the integrated hydrogels extremely complicated, and the potential immunogenicity and biotoxicity of these hydrogel components cause substantial anxiety, greatly restricting their clinical applications [25]. Therefore, alternative strategy to prepare biocompatible microenvironment modulator with simple composition capable of spatially and temporally addressing the four DU microenvironment-related issues is highly desirable in DU management. 


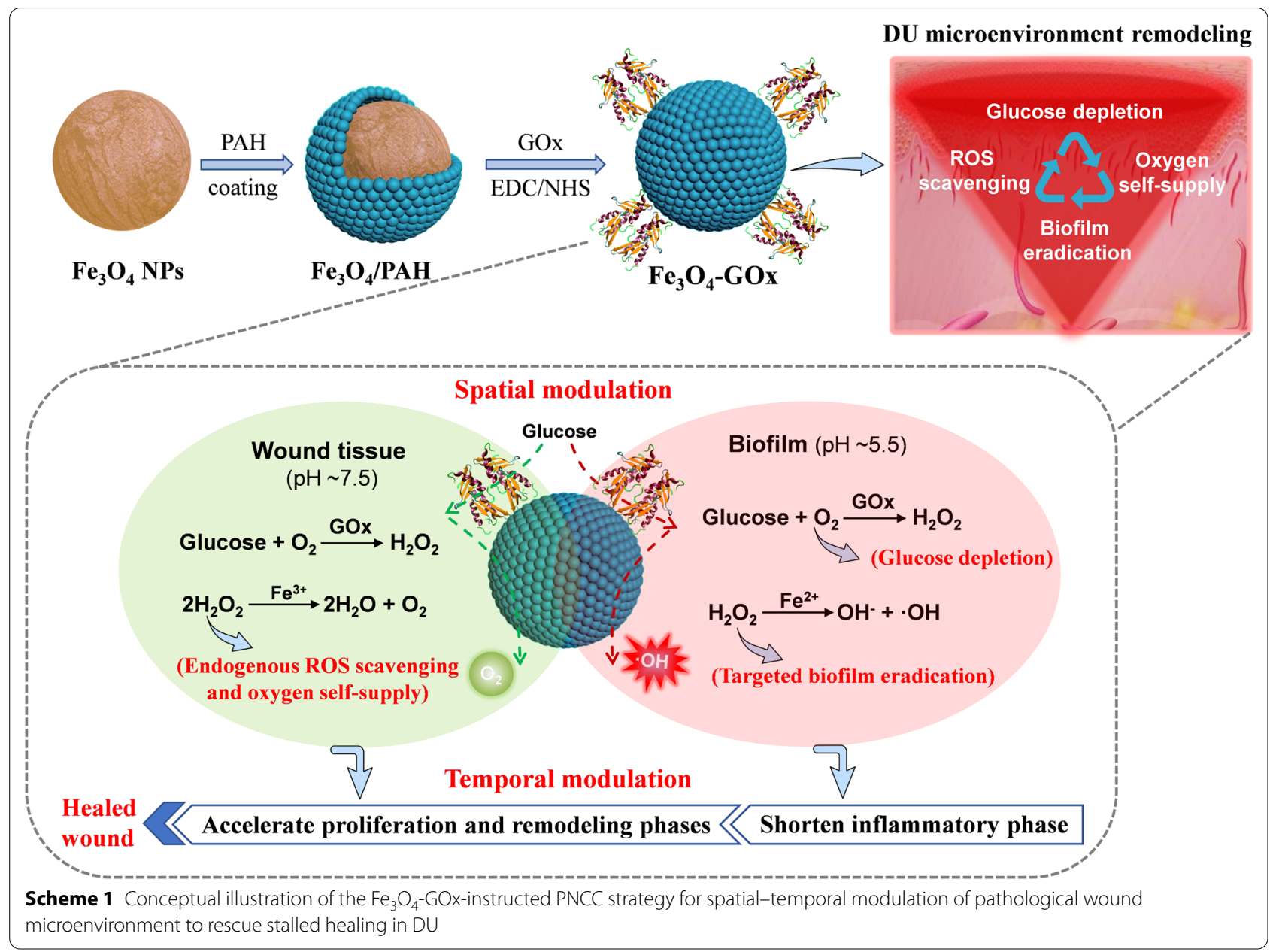

Research into enzyme cascade catalysis may provide insight into potential strategies for the development of desired biocompatible DU microenvironment modulator. Enzymes are natural biomaterials capable of catalyzing various chemical reactions to mediate biological processes [26]. In living organisms, enzyme cascade systems have been evolved by confining cooperating enzymes within compartments to boost their catalytic performances without the separation of intermediates for spatial-temporal modulation of complex physiological microenvironment $[27,28]$. Inspired by this, enzymemedicated cascade catalysis strategy could be developed for DU microenvironment modulation. However, due to the limitation of the specificity of enzyme-catalyzed reactions as well as high cost and harsh usage condition [29], enzyme cascade catalysis systems with simple composition that can concurrently address the four DU-related issues remain elusive. Recently, investigation on nanozyme has demonstrated that some nanomaterials (e.g., metal-oxide and carbon-based nanoparticles) possess distinctive pathological conditions-switchable multiple enzyme-like activities, indicating the feasibility of employing one nanozyme to catalyze cascade reactions [30-33]. Therefore, we hypothesize that by combing the concept of enzyme cascade catalysis and nanozyme in the design of pathological wound microenvironment spatial-temporal modulator, a robust strategy for DU management could be developed.

Herein, we introduce a pH-switchable nanozyme cascade catalysis (PNCC) strategy for spatial-temporal modulation of pathological wound microenvironment to rescue stalled healing in DU (Scheme 1). The nanozyme we designed (named $\mathrm{Fe}_{3} \mathrm{O}_{4}$-GOx) is composed of an iron oxide nanoparticle $\left(\mathrm{Fe}_{3} \mathrm{O}_{4} \mathrm{NPs}\right)$ core and a glucose oxidase (GOx) shell. GOx is an oxidoreductase that can catalyze the oxidization of glucose to produce hydrogen peroxide $\left(\mathrm{H}_{2} \mathrm{O}_{2}\right)$ [34]. $\mathrm{Fe}_{3} \mathrm{O}_{4}$ NPs approved by the United States Food and Drug Administration (FDA), exhibits intrinsic $\mathrm{pH}$-dependent peroxidase (POD) and catalase (CAT)-like activities that can catalyze the decomposition of $\mathrm{H}_{2} \mathrm{O}_{2}$ into oxygen and hydroxyl radicals $(\cdot \mathrm{OH})$, respectively [35-37]. Therefore, $\mathrm{pH}$-switchable GOx/ 
POD and GOx/CAT cascade reactions can be carried out in the $\mathrm{Fe}_{3} \mathrm{O}_{4}$-GOx with closely co-localized GOx and $\mathrm{Fe}_{3} \mathrm{O}_{4}$ NPs. Specifically, the GOx/POD cascade reaction generating consecutive fluxes of toxic hydroxyl radical spatially targets the acidic biofilm $(\mathrm{pH} \sim 5.5)$, and eradicates biofilm to shorten the inflammatory phase and initiate the normal wound healing of proliferation and remodeling. Furthermore, the GOx/CAT cascade reaction producing consecutive fluxes of oxygen spatially targets the neutral wound tissue, and accelerates the proliferation and remodeling phases of wound healing by addressing the issues of hyperglycemia, hypoxia, and excessive oxidative stress. The shortened inflammatory phase temporally coupled with accelerated proliferation and remodeling phases significantly speed up the normal orchestrated wound-healing cascades, enabling efficient DU treatment.

\section{Results and discussion}

Preparation and characterization of $\mathrm{Fe}_{3} \mathrm{O}_{4}-\mathrm{GOx}$

In typical experiments, magnetic $\mathrm{Fe}_{3} \mathrm{O}_{4} \mathrm{NPs}$ was first synthesized based on a thermal decomposition method (Additional file 1: Figs. S1 and S2) [38, 39], and $\mathrm{Fe}_{3} \mathrm{O}_{4}$-GOx nanozyme was then prepared by poly (allylamine hydrochloride) (PAH) electrostatic coating and GOx covalent modification (Scheme 1). The transmission electron microscopy (TEM) image shows that the prepared $\mathrm{Fe}_{3} \mathrm{O}_{4}$-GOx nanozyme had a homogeneous and well-defined spherical structure with an average size of $12.7 \pm 2.5 \mathrm{~nm}$ (Fig. 1a). The UV-vis absorption spectra show that the $\mathrm{Fe}_{3} \mathrm{O}_{4}$-GOx nanozyme exhibited the characteristic absorption peaks of GOx at around 377 and $455 \mathrm{~nm}$ respectively, confirming the successful conjugation of GOx molecules (Fig. 1b). The loading amount of GOx on $\mathrm{Fe}_{3} \mathrm{O}_{4}$-GOx nanozyme (1.5 $\pm 0.2 \mathrm{mg}$ of GOx per $\mathrm{mg}$ of iron element) was quantitatively determined by bicinchoninic acid (BCA) assay (Additional file 1: Fig. S3) [40]. In addition, the whole preparation process of $\mathrm{Fe}_{3} \mathrm{O}_{4}$-GOx nanozyme could be easily monitored and confirmed by the results of reversed zeta potential (Fig. 1c) and increased hydrodynamic size (Additional file 1: Fig. S4). Moreover, no significant increase of hydrodynamic size was found for $\mathrm{Fe}_{3} \mathrm{O}_{4}$-GOx nanozyme during long-term storage in PBS a)

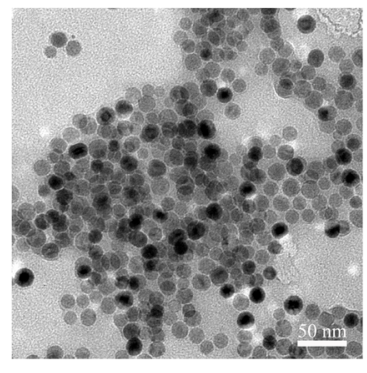

b)

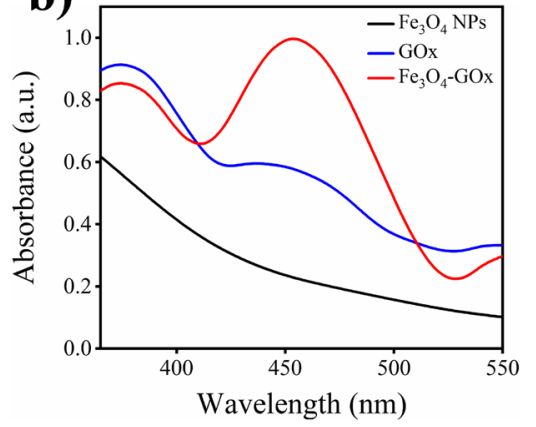

c)

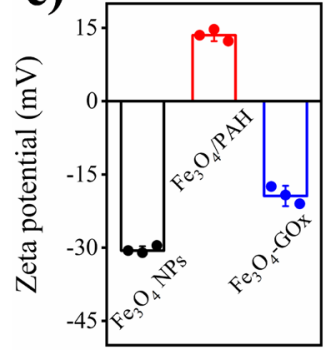

d)

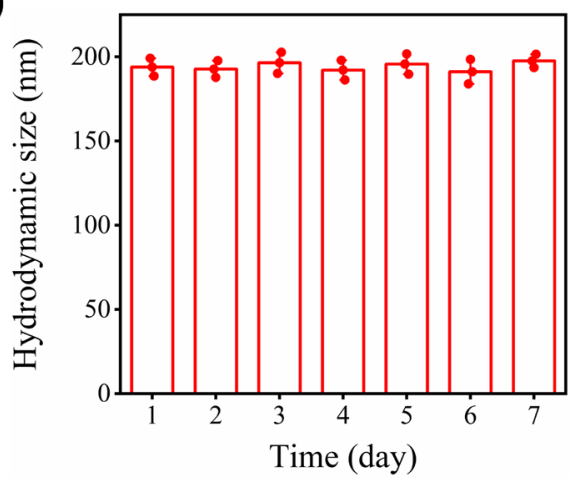

e)

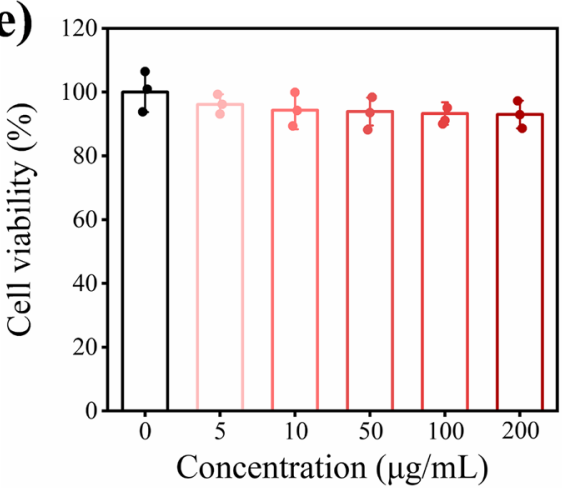

Fig. 1 Characterization of $\mathrm{Fe}_{3} \mathrm{O}_{4}-\mathrm{GOx}$. a TEM image of $\mathrm{Fe}_{3} \mathrm{O}_{4}-\mathrm{GO}$ x nanozyme. $\mathbf{b}$ UV-vis absorption spectra of Fe $\mathrm{O}_{4} \mathrm{NPs}_{\text {, }} \mathrm{GOx}$, and Fe $\mathrm{O}_{4}-\mathrm{GOx}$ nanozyme. c Zeta potentials of $\mathrm{Fe}_{3} \mathrm{O}_{4} \mathrm{NPS}$, PAH-coated $\mathrm{Fe}_{3} \mathrm{O}_{4} \mathrm{NPS}\left(\mathrm{Fe}_{3} \mathrm{O}_{4} / \mathrm{PAH}\right)$, and $\mathrm{Fe}_{3} \mathrm{O}_{4}-\mathrm{GO}$ nanozyme in DI water. $\mathbf{d}$ Hydrodynamic diameter of $\mathrm{Fe}_{3} \mathrm{O}_{4}$-GOx nanozyme in PBS buffer (0.01 M, pH 7.4) during 7 days of storage. e Viability of HUVEC cells after incubation with Fe $\mathrm{O}_{4}$-GOx nanozyme at various concentrations of iron element for $24 \mathrm{~h}$. In $\mathbf{c}-\mathbf{e}$, the values of zeta potential, hydrodynamic diameter and cell viability represent the mean of three independent experiments, and the error bars indicate the standard deviation (SD) from the mean 
buffer at different temperatures $\left(4\right.$ and $\left.25^{\circ} \mathrm{C}\right)$, revealing the high structural stability and excellent solubility of $\mathrm{Fe}_{3} \mathrm{O}_{4}$-GOx in an aqueous environment (Fig. $1 \mathrm{~d}$ and Additional file 1: Fig. S5). Furthermore, from the methyl thiazolyl tetrazolium (MTT) assay, it was found that the human umbilical vein endothelial cells (HUVEC) possessed high viability ( $\geq 93 \%$ ) after incubation with $\mathrm{Fe}_{3} \mathrm{O}_{4}$-GOx nanozyme at various concentrations, demonstrating the outstanding in vitro biocompatibility of $\mathrm{Fe}_{3} \mathrm{O}_{4}$-GOx nanozyme (Fig. 1e). This excellent in vivo biocompatibility is reasonable by considering the low biotoxicity of GOx and clinically approved $\mathrm{Fe}_{3} \mathrm{O}_{4} \mathrm{NPs}$ $[34,41]$.

\section{Neutral pH-switchable GOx/CAT cascade catalysis of $\mathrm{Fe}_{3} \mathrm{O}_{4}$-GOx}

By assembling GOx with $\mathrm{Fe}_{3} \mathrm{O}_{4} \mathrm{NPs}$, the $\mathrm{Fe}_{3} \mathrm{O}_{4}$-GOx is expected to acquire the catalytic activities of $\mathrm{GOx}$, CAT and POD, and can elicit coupled GOx/CAT and GOx/POD cascade reactions. To confirm this expectation, the $\mathrm{GOx}$ activity of $\mathrm{Fe}_{3} \mathrm{O}_{4}-\mathrm{GOx}$ to realize glucose depletion was first investigated. As shown in Fig. 2a, the glucose concentration of diabetic blood sample significantly decreased with the increase of $\mathrm{Fe}_{3} \mathrm{O}_{4}$-GOx nanozyme (blood glucose concentration was reduced by $62 \%$ after incubation with $200 \mu \mathrm{g} / \mathrm{mL}$ of $\mathrm{Fe}_{3} \mathrm{O}_{4}$-GOx for $5 \mathrm{~min}$ ), indicating the depletion of glucose. Meanwhile, $\mathrm{H}_{2} \mathrm{O}_{2}$ was detected in the glucose solution after

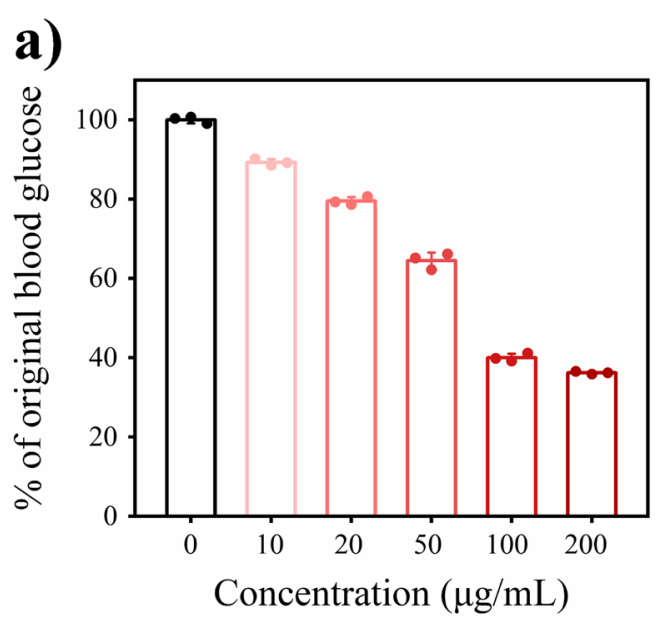

b)

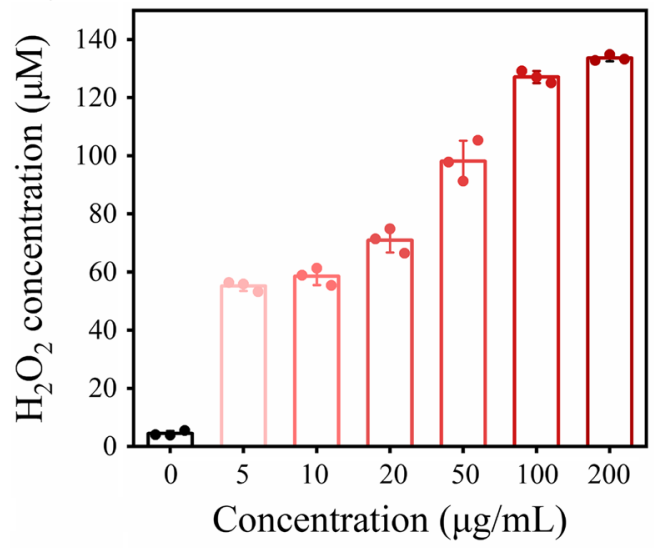

c)

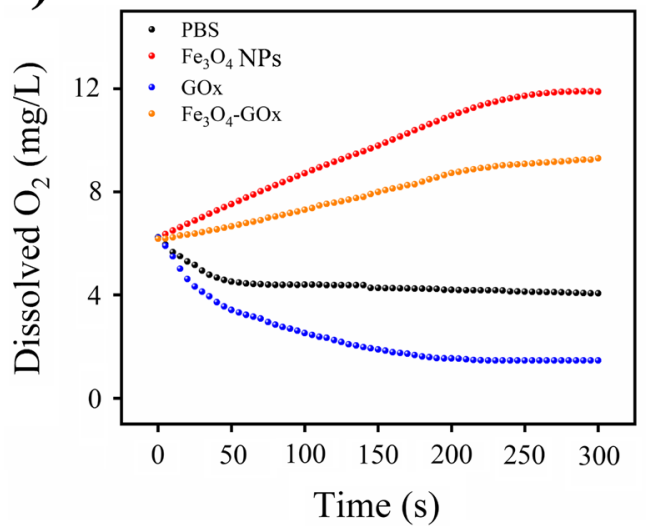

d)

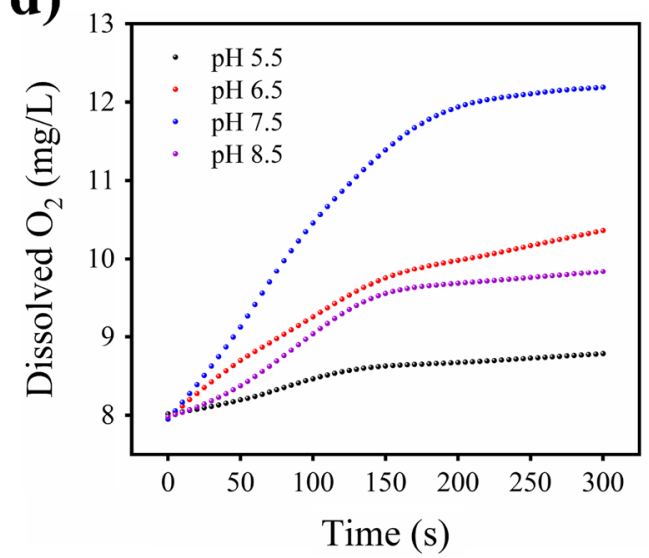

Fig. 2 Neutral pH-switchable GOx/CAT cascade catalysis capability of $\mathrm{Fe}_{3} \mathrm{O}_{4}-\mathrm{GOx}$. a The depletion of glucose in diabetic blood sample (containing around $20 \mathrm{mM}$ of glucose) after incubation with different concentrations of $\mathrm{Fe}_{3} \mathrm{O}_{4}-\mathrm{GOx}$ nanozyme for $5 \mathrm{~min}$. $\mathbf{b}$ The concentration of $\mathrm{H}_{2} \mathrm{O}_{2}$ generated in glucose solution $\left(20 \mathrm{mM}\right.$, pH 7.5) after incubation with different concentrations of $\mathrm{Fe}_{3} \mathrm{O}_{4}$ - $\mathrm{GOx}$ nanozyme for 5 min. $\mathbf{c}$ The change of dissolved $\mathrm{O}_{2}$ concentration in the mixed solution of glucose $(20 \mathrm{mM})$ and $\mathrm{H}_{2} \mathrm{O}_{2}(7 \mathrm{mM})$ in $\mathrm{pH} 7.4$ after incubation with $\mathrm{PBS}, \mathrm{Fe}_{3} \mathrm{O}_{4} \mathrm{NPs}(200 \mu \mathrm{g} / \mathrm{mL}$ of iron element), $\mathrm{GOx}\left(300 \mathrm{\mu g} / \mathrm{mL}\right.$ ) and $\mathrm{Fe}_{3} \mathrm{O}_{4}-\mathrm{GOx}\left(200 \mathrm{\mu g} / \mathrm{mL}\right.$ of iron element) for $5 \mathrm{~min}$, respectively. $\mathbf{d}$ The change of dissolved $\mathrm{O}_{2}$ concentration in the solution of glucose $(20 \mathrm{mM})$ and $\mathrm{H}_{2} \mathrm{O}_{2}(10 \mathrm{mM})$ with different $\mathrm{pH}$ values after incubation with $\mathrm{Fe}_{3} \mathrm{O}_{4}-\mathrm{GOx}(200 \mathrm{\mu g} / \mathrm{mL}$ of iron element) for $5 \mathrm{~min}$. In $\mathbf{a}$ and $\mathbf{b}$, the values of glucose consumption (\% of original blood glucose) and $\mathrm{H}_{2} \mathrm{O}_{2}$ concentration represent the mean of three independent experiments, and the error bars indicate the SD from the mean 
incubation with $\mathrm{Fe}_{3} \mathrm{O}_{4}$-GOx nanozyme, and its concentration was found to be gradually increased with the increase of $\mathrm{Fe}_{3} \mathrm{O}_{4}$-GOx nanozyme (Fig. 2b), demonstrating the oxidation of glucose in the presence of $\mathrm{Fe}_{3} \mathrm{O}_{4}$-GOx nanozyme. The results of glucose depletion and $\mathrm{H}_{2} \mathrm{O}_{2}$ production together prove the GOx activity of $\mathrm{Fe}_{3} \mathrm{O}_{4}$-GOx nanozyme. Additional file 1: Fig. S6 shows the production of $\mathrm{H}_{2} \mathrm{O}_{2}$ in glucose solution after incubation with $\mathrm{Fe}_{3} \mathrm{O}_{4}$-GOx nanozyme for different times. It was found that the concentration of $\mathrm{H}_{2} \mathrm{O}_{2}$ gradually decreased with the extension of glucose and $\mathrm{Fe}_{3} \mathrm{O}_{4}-\mathrm{GOx}$ incubation time, indicating the decomposition of $\mathrm{H}_{2} \mathrm{O}_{2}$ produced in glucose oxidation. This phenomenon may be ascribed to the occurrence of GOx/CAT and GOx/POD cascade reactions in the $\mathrm{Fe}_{3} \mathrm{O}_{4}$ - $\mathrm{GOx} /$ glucose system, due to the CAT and POD activities of $\mathrm{Fe}_{3} \mathrm{O}_{4}$-GOx nanozyme to catalyze the decomposition of $\mathrm{H}_{2} \mathrm{O}_{2}$. The co-existent POD and CAT-like activities of $\mathrm{Fe}_{3} \mathrm{O}_{4}$-GOx was attributed to the mixed valence of $\mathrm{Fe}^{2+}$ and $\mathrm{Fe}^{3+}$, as evidenced by the result of X-ray photoelectron spectroscopy (XPS) analysis (Additional file 1: Fig. S7).

To assess the CAT activity of $\mathrm{Fe}_{3} \mathrm{O}_{4}-\mathrm{GOx}$ and confirm the occurrence of coupled GOx/CAT cascade reaction in the $\mathrm{Fe}_{3} \mathrm{O}_{4}$ - $\mathrm{GOx} /$ glucose system, $\mathrm{Fe}_{3} \mathrm{O}_{4}$ - $\mathrm{GOx}$ nanozyme was incubated with the mixture of glucose and $\mathrm{H}_{2} \mathrm{O}_{2}$ (glucose- $\mathrm{H}_{2} \mathrm{O}_{2}$ ), and the production of $\mathrm{O}_{2}$ was evaluated. As shown in Fig. 2c, considerable level of $\mathrm{O}_{2}$ was detected in the systems of $\mathrm{Fe}_{3} \mathrm{O}_{4}$ - $\mathrm{GOx} /$ glucose- $\mathrm{H}_{2} \mathrm{O}_{2}$ and $\mathrm{Fe}_{3} \mathrm{O}_{4}$ NPs/ glucose $-\mathrm{H}_{2} \mathrm{O}_{2}$ rather than the control systems of PBS/ glucose- $\mathrm{H}_{2} \mathrm{O}_{2}$ and $\mathrm{GOx} /$ glucose $-\mathrm{H}_{2} \mathrm{O}_{2}$, indicating the remarkable CAT activity of $\mathrm{Fe}_{3} \mathrm{O}_{4}-\mathrm{GOx}$ and $\mathrm{Fe}_{3} \mathrm{O}_{4}$ NPs. Moreover, compared to the system of $\mathrm{Fe}_{3} \mathrm{O}_{4} \mathrm{NPs} / \mathrm{glu}-$ cose- $\mathrm{H}_{2} \mathrm{O}_{2}$, a relatively lower $\mathrm{O}_{2}$ concentration was found in the system of $\mathrm{Fe}_{3} \mathrm{O}_{4}-\mathrm{GOx} /$ glucose- $\mathrm{H}_{2} \mathrm{O}_{2}$ due to the $\mathrm{O}_{2}$ consumption during glucose oxidation, confirming the occurrence of coupled $\mathrm{GOx} / \mathrm{CAT}$ cascade reaction in the system of $\mathrm{Fe}_{3} \mathrm{O}_{4}-\mathrm{GOx} /$ glucose- $\mathrm{H}_{2} \mathrm{O}_{2}$. This result indicates that the toxic $\mathrm{H}_{2} \mathrm{O}_{2}$ produced in glucose oxidation as well as oxidative stress progression of DU wound can be converted into beneficial $\mathrm{O}_{2}$ by $\mathrm{Fe}_{3} \mathrm{O}_{4}$-GOx, making synergistic tissue hypoxia and oxidative stress amelioration in DU become possible and forming a self-oxygen supply system to accelerate glucose oxidation. In addition, the production of $\mathrm{O}_{2}$ in the $\mathrm{Fe}_{3} \mathrm{O}_{4}$ - $\mathrm{GOx} /$ glucose$\mathrm{H}_{2} \mathrm{O}_{2}$ systems with different $\mathrm{pH}$ values was assessed. As shown in Fig. 2d, the system of $\mathrm{Fe}_{3} \mathrm{O}_{4}$ - $\mathrm{GOx} /$ glucose$\mathrm{H}_{2} \mathrm{O}_{2}$ under neutral ( $\mathrm{pH}$ 7.5) and slightly acidic ( $\mathrm{pH}$ 6.5) conditions produced much higher level of $\mathrm{O}_{2}$ compared to that under acidic ( $\mathrm{pH} 5.5)$ and alkaline $(\mathrm{pH}$ 8.5) conditions, showing a neutral environment-preferred GOx/ CAT cascade reaction. This $\mathrm{pH}$-dependent CAT activity of $\mathrm{Fe}_{3} \mathrm{O}_{4}$-GOx nanozyme is consistent with the $\mathrm{Fe}_{3} \mathrm{O}_{4}$ NPs previously reported [36]. The oxidation process of glucose catalyzed by GOx is accompanied by the formation of gluconic acid, which would decrease the $\mathrm{pH}$ of the surrounding microenvironment and further affect the CAT-like activity of $\mathrm{Fe}_{3} \mathrm{O}_{4}$-GOx. Additional file 1: Fig. S8 shows the $\mathrm{pH}$ change of the $\mathrm{Fe}_{3} \mathrm{O}_{4}-\mathrm{GOx} /$ glucose system. It was found that the gluconic acid generated basically did not affect the $\mathrm{pH}$ value of the $\mathrm{Fe}_{3} \mathrm{O}_{4}$-GOx/glucose system ( $\mathrm{pH}$ only dropped by $0.32 \pm 0.14$ within $60 \mathrm{~min}$ ) at the glucose working concentration $(20 \mathrm{mM})$ we employed. Predictably, such a small $\mathrm{pH}$ change will not affect the CAT-like activity as well as the GOx/CAT cascade catalysis performance of $\mathrm{Fe}_{3} \mathrm{O}_{4}$-GOx/glucose system.

\section{Acidic $\mathrm{pH}$-switchable GOx/POD cascade catalysis of $\mathrm{Fe}_{3} \mathrm{O}_{4}$-GOx}

The POD activity of $\mathrm{Fe}_{3} \mathrm{O}_{4}$-GOx and the occurrence of coupled GOx/POD cascade reaction in the system of $\mathrm{Fe}_{3} \mathrm{O}_{4}$-GOx/glucose were evaluated. As shown in Fig. 3a, the $\mathrm{Fe}_{3} \mathrm{O}_{4}$-GOx nanozyme rapidly catalyzed the oxidation of 3,3',5,5'-tetramethylbenzidine (TMB, a POD substrate) in the presence of glucose, and produced a yellow-colored oxidation product with an absorbance maximum around $450 \mathrm{~nm}$ after adding sulfuric acid as the reaction termination reagent [42], showing excellent POD-like activity and confirming the occurrence of coupled GOx/POD cascade reaction. In contrast, TMB oxidation was found to be very weak in the systems of PBS/glucose, $\mathrm{Fe}_{3} \mathrm{O}_{4} \mathrm{NPs} /$ glucose and GOx/glucose. Moreover, the $\mathrm{Fe}_{3} \mathrm{O}_{4}$-GOx/glucose system achieved a higher TMB oxidation efficiency in the conditions of $\mathrm{pH} 5.5$ and $\mathrm{pH} 6.5$ than that in $\mathrm{pH} 7.5$ and $\mathrm{pH}$ 8.5, exhibiting an acidic environment-preferred GOx/POD cascade reaction (Fig. 3b). In addition to TMB oxidation, similar results were obtained using the POD substrate of 2,2'-azinobis(3-ethylbenzothiazoline-6-sulfonic acid) diammonium salt (ABTS) and o-phenylenediamine (OPD), respectively (Additional file 1: Fig. S9) [43, 44]. Theoretically, the coupled GOx/POD cascade reaction can generate the $\cdot \mathrm{OH}$ in the $\mathrm{Fe}_{3} \mathrm{O}_{4}$ - $\mathrm{GOx} /$ glucose system. Therefore, the formation of $\cdot \mathrm{OH}$ in the $\mathrm{Fe}_{3} \mathrm{O}_{4}$ - $\mathrm{GOx} /$ glucose system was assessed based on the methylene blue (MB) degradation and terephthalic acid (TA) fluorescent assays $[45,46]$. As shown in Fig. $3 c$ and Additional file 1: Fig. S10, blue-colored $\mathrm{MB}$ was gradually degraded to generate colorless $\mathrm{MB}-\mathrm{OH}$ only in the system of $\mathrm{Fe}_{3} \mathrm{O}_{4}$ - $\mathrm{GOx} /$ glucose, indicating the formation of $\cdot \mathrm{OH}$. Consistent with $\mathrm{MB}$ degradation result, fluorescent $\mathrm{TAOH}$ derived from the reaction of TA and . $\mathrm{OH}$ was only detected in the system of $\mathrm{Fe}_{3} \mathrm{O}_{4}$-GOx/glucose, and showed an acidic environment-preferred generation trend (Additional file 1: Fig. S11 and Fig. 3d). Similar results were obtained by the electron spin resonance (ESR) analysis using the spin trap molecule of DMPO to capture $\cdot \mathrm{OH}$ generated in the system of $\mathrm{Fe}_{3} \mathrm{O}_{4}$-GOx/glucose (Additional file 1: Fig. 

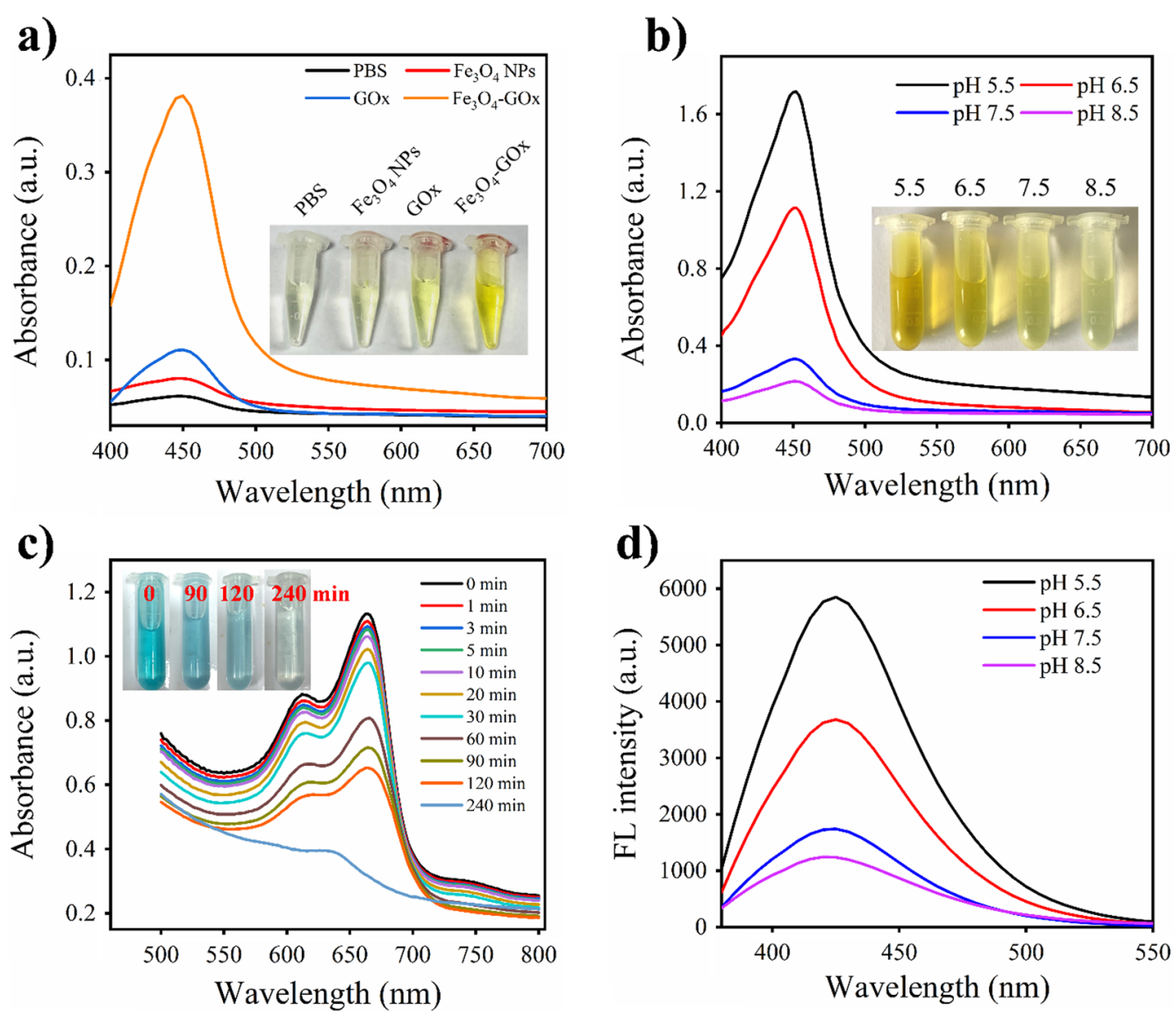

Fig. 3 Acidic $\mathrm{pH}$-switchable $\mathrm{GOx} / \mathrm{POD}$ cascade catalysis capability of $\mathrm{Fe}_{3} \mathrm{O}_{4}-\mathrm{GOx}$. a UV-vis absorption spectra of glucose solution ( $20 \mathrm{mM}$, pH 5.5) after incubation with PBS, $\mathrm{Fe}_{3} \mathrm{O}_{4} \mathrm{NPs}\left(200 \mu \mathrm{g} / \mathrm{mL}\right.$ of iron element), GOx $(300 \mu \mathrm{g} / \mathrm{mL})$ and $\mathrm{Fe}_{3} \mathrm{O}_{4}-\mathrm{GO}$ ( $(200 \mu \mathrm{g} / \mathrm{mL}$ of iron element) for $5 \mathrm{~min}$, respectively, in the presence of TMB and sulfuric acid. The inset shows the corresponding photographs of the four mixtures. $\mathbf{b} U \mathrm{~V}$-vis absorption spectra of glucose solution $\left(20 \mathrm{mM}\right.$ ) with different $\mathrm{pH}$ values after incubation with $\mathrm{Fe}_{3} \mathrm{O}_{4}$ - $\mathrm{GOx}(200 \mathrm{\mu g} / \mathrm{mL}$ of iron element) for 5 min in the presence of TMB and sulfuric acid. The inset shows the corresponding photographs of the four mixtures. $\mathbf{c ~ M B}$ degradation in the mixture of $\mathrm{Fe}_{3} \mathrm{O}_{4}-\mathrm{GOx}$ ( $200 \mathrm{\mu g} / \mathrm{mL}$ of iron element) and glucose $(20 \mathrm{mM}$ ) within $240 \mathrm{~min}$ in the condition of pH 5.5. The inset shows the corresponding photographs of the mixture at four scheduled time points. d TA fluorescent assay in the mixture of $\mathrm{Fe}_{3} \mathrm{O}_{4}-\mathrm{GOx}(200 \mu \mathrm{g} / \mathrm{mL}$ of iron element) and glucose (20 mM) with different $\mathrm{pH}$ values

S12). By considering the unique pathological acidic condition of biofilm microenvironment $[47,48]$, the acidic pH-dependent GOx/POD cascade catalysis activity of $\mathrm{Fe}_{3} \mathrm{O}_{4}$-GOx to generate consecutive fluxes of toxic $\cdot \mathrm{OH}$ lays solid foundation for precise targeted biofilm elimination in DU.

\section{In vitro antimicrobial capability of $\mathrm{Fe}_{3} \mathrm{O}_{4}-\mathrm{GOx}$}

As an important ROS substance, $\mathrm{OH}$ produced by $\mathrm{Fe}_{3} \mathrm{O}_{4}$-GOx under acidic condition will greatly increase the intracellular level of ROS as well as biomacromolecules oxidative damage of bacteria, possessing robust antimicrobial capability. To verify this conclusion, dichlorodifluorescein (DCF, a fluorescent marker generated from dichlorodihydrofluorescein dye by ROS) staining as well as biomacromolecules oxidative damage assay of bacteria were carried out. Figure 4a shows the DCF staining images of bacterial strains of Escherichia coli (E. coli, gram-negative) and methicillin-resistant Staphylococcus aureus (MRSA, gram-positive) in the different treatment groups. It was found that $E$. coli and MRSA in the treatment group of $\mathrm{Fe}_{3} \mathrm{O}_{4}$-GOx/glucose exhibited much greater DCF fluorescence than the control group (PBS/ glucose), indicating that the intracellular ROS level was significantly increased in bacteria after nanozyme treatment. In addition, enhanced generation of malondialdehyde (MDA) and carbonylated proteins was observed in bacteria treated by $\mathrm{Fe}_{3} \mathrm{O}_{4}$-GOx/glucose compared to the control (PBS/glucose), demonstrating the occurrence of more serious intracellular oxidative damage of 


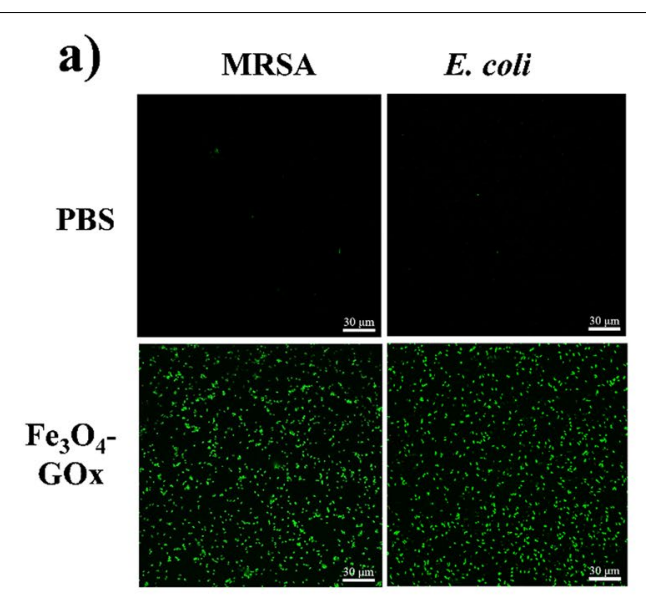

c)

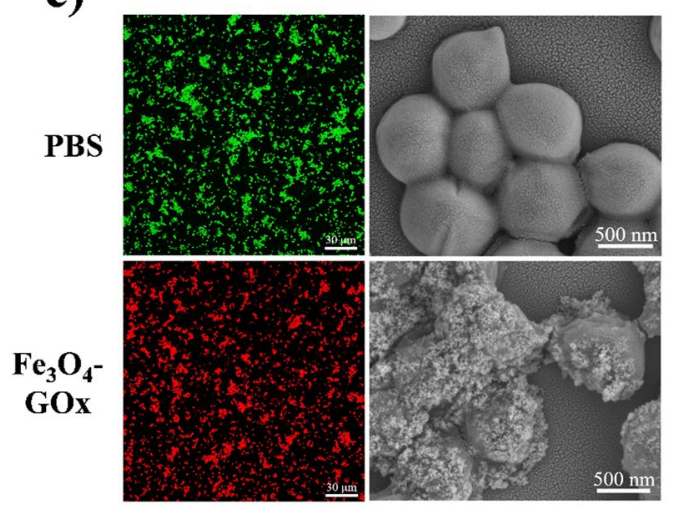

b)

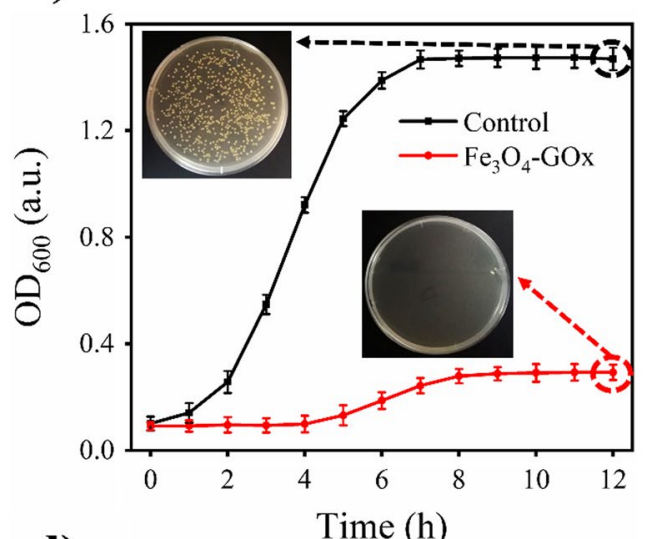

d)

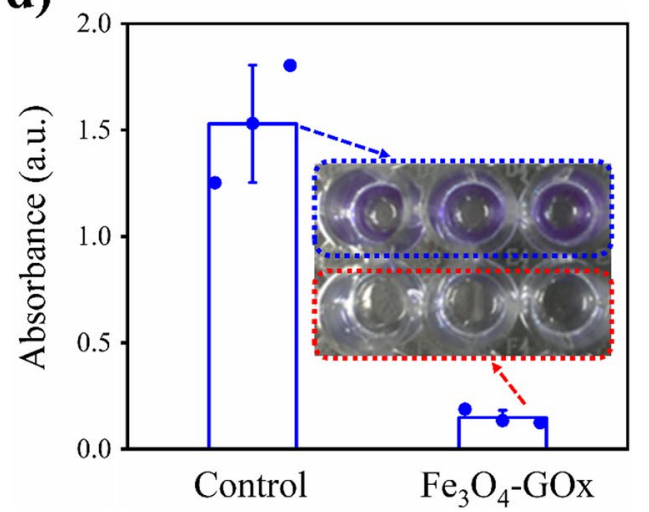

Fig. 4 In vitro antimicrobial performance of $\mathrm{Fe}_{3} \mathrm{O}_{4}-\mathrm{GOX}$. a Typical DCF staining images of E. coli and MRSA treated by the system of $\mathrm{Fe}_{3} \mathrm{O}_{4}-\mathrm{GOX} /$ glucose and PBS/glucose, respectively. $\mathbf{b}$ Growth curves of MRSA treated by the system of $\mathrm{Fe}_{3} \mathrm{O}_{4}-\mathrm{GO} / \mathrm{glucose}$ and control (PBS/glucose) respectively, and the inset shows the corresponding photographs of culture plates of MRSA taken from the two treatment groups at the time point of $12 \mathrm{~h}$. c Representative SEM and live/dead staining images of MRSA treated by the system of $\mathrm{Fe}_{3} \mathrm{O}_{4}-\mathrm{GOx} / \mathrm{glucose}$ and PBS/glucose, respectively. d Crystal violet staining image and its corresponding absorbance for integrated MRSA biofilm treated by the system of Fe $\mathrm{O}_{4}$ - $\mathrm{GOx} / \mathrm{glucose}$ and control (PBS/glucose), respectively. The inset shows the corresponding photographs of crystal violet staining of MRSA biofilm in the two treatment groups. In above experiments, the concentrations of $\mathrm{Fe}_{3} \mathrm{O}_{4}-\mathrm{GOx}$, glucose and bacteria used was $200 \mathrm{\mu g} / \mathrm{mL}$ (iron element), $20 \mathrm{mM}$ and $10^{7} \mathrm{CFU} / \mathrm{mL}$, respectively. In $\mathbf{b}$ and $\mathbf{d}$, the values of $\mathrm{OD}_{600}$ and crystal violet absorbance represent the mean of three independent experiments, and the error bars indicate the SD from the mean

biomacromolecules (membrane lipid and protein) after nanozyme treatment (Additional file 1: Figs. S13 and S14). The higher level of intracellular ROS as well as biomacromolecules oxidative damage will inevitably cause the death of bacteria. Therefore, the growth of $E$. coli and MRSA after nanozyme treatment was subsequently investigated, and the results are shown in Additional file 1: Fig. S15 and Fig. 4b. It was found that E. coli and MRSA bacterial growth was indeed extremely inhibited in the treatment group of $\mathrm{Fe}_{3} \mathrm{O}_{4}$-GOx/glucose compared to the control (PBS/glucose) as expected, confirming the broad-spectrum antimicrobial activity of nanozyme.

To investigate the specific mechanism behind the antimicrobial activity of $\mathrm{Fe}_{3} \mathrm{O}_{4}$-GOx nanozyme, live/ dead bacterial staining assay and scanning electronic microscopy (SEM)-based bacterial morphology study were performed. As shown in Fig. 4c and Additional file 1: Fig. S16, E. coli and MRSA showed clear and smooth bodies and was stained green by the nucleic acid dye of SYTO 9 in the treatment group of PBS/glucose, exhibiting a normal survival state of living bacteria. In sharp contrast, cellular deformation and surface collapse as well as propidium iodide dye (red color, only penetrate bacteria with destroyed structure) staining were obviously found for E. coli and MRSA in the treatment group of $\mathrm{Fe}_{3} \mathrm{O}_{4}$-GOx/glucose, suggesting the bacterial cell wall and membrane disruption-involved mechanism behind the broad-spectrum antimicrobial activity of $\mathrm{Fe}_{3} \mathrm{O}_{4}-\mathrm{GOx}$ nanozyme [49]. This conclusion could be further proved by the experiment result 
of bacterial biomacromolecules leakage. As shown in Additional file 1: Figs. S17 and S18, the level of protein and DNA/RNA leakage in bacteria treated by $\mathrm{Fe}_{3} \mathrm{O}_{4}$-GOx/glucose was greatly improved compared to the control (PBS/glucose), indicating the structure disruption of bacteria after nanozyme treatment. Bacterial biofilm, a bacterial community wrapped by self-produced extracellular polymeric substances, is the main form of bacterial infection in DU wound $[7,50]$. Therefore, in addition to planktonic bacteria, the antimicrobial activity of $\mathrm{Fe}_{3} \mathrm{O}_{4}$-GOx toward biofilm was also assessed. As shown in Additional file 1: Fig. S19, the formation of MRSA and E. coli biofilm was effectively inhibited by the $\mathrm{Fe}_{3} \mathrm{O}_{4}$-GOx/glucose. In addition to biofilm formation inhibition, integrated MRSA and E. coli biofilm were almost eradicated in the treatment group of $\mathrm{Fe}_{3} \mathrm{O}_{4}$-GOx/glucose while the biofilms remained intact in the control group (PBS/glucose) (Fig. $4 \mathrm{~d}$ and Additional file 1: Fig. S20). This result demonstrates the outstanding capability of $\mathrm{Fe}_{3} \mathrm{O}_{4}$-GOx nanozyme for biofilm eradication and paves the way for subsequent in vivo biofilm infection treatment in DU wound.

\section{In vivo performance of $\mathrm{Fe}_{3} \mathrm{O}_{4}-\mathrm{GO}$ for $\mathrm{DU}$ treatment}

To conduct in vivo DU treatment, an MRSA biofilminfected wound model of diabetic mouse was employed to mimic the clinical symptoms of hyperglycemia, hypoxia, excessive oxidative stress, and biofilm infection of DU. This mouse model was constructed by creating a full-thickness wound extending through the panniculus carnosus in the back of genetically modified diabetic mouse followed by MRSA inoculation to form biofilm in situ (Fig. 5a). To evaluate the performance of $\mathrm{Fe}_{3} \mathrm{O}_{4}$-GOx nanozyme for in vivo DU treatment, MRSA biofilm-infected diabetic wound was treated by $\mathrm{Fe}_{3} \mathrm{O}_{4}$-GOx and wound healing process was qualitatively and quantitatively analyzed. Four treatment groups including $\mathrm{PBS}, \mathrm{Fe}_{3} \mathrm{O}_{4} \mathrm{NPs}, \mathrm{GOx}$, and $\mathrm{Fe}_{3} \mathrm{O}_{4}$-GOx were divided in our experiments. Figure $5 \mathrm{~b}$ shows typical photographs of MRSA biofilm-infected diabetic wound within 15 days of treatment in the four treatment groups, and the corresponding graphical representations of the quantitative measurement of wound areas are presented in Fig. 5c. It was found that compared to the treatment group of PBS, wound healing

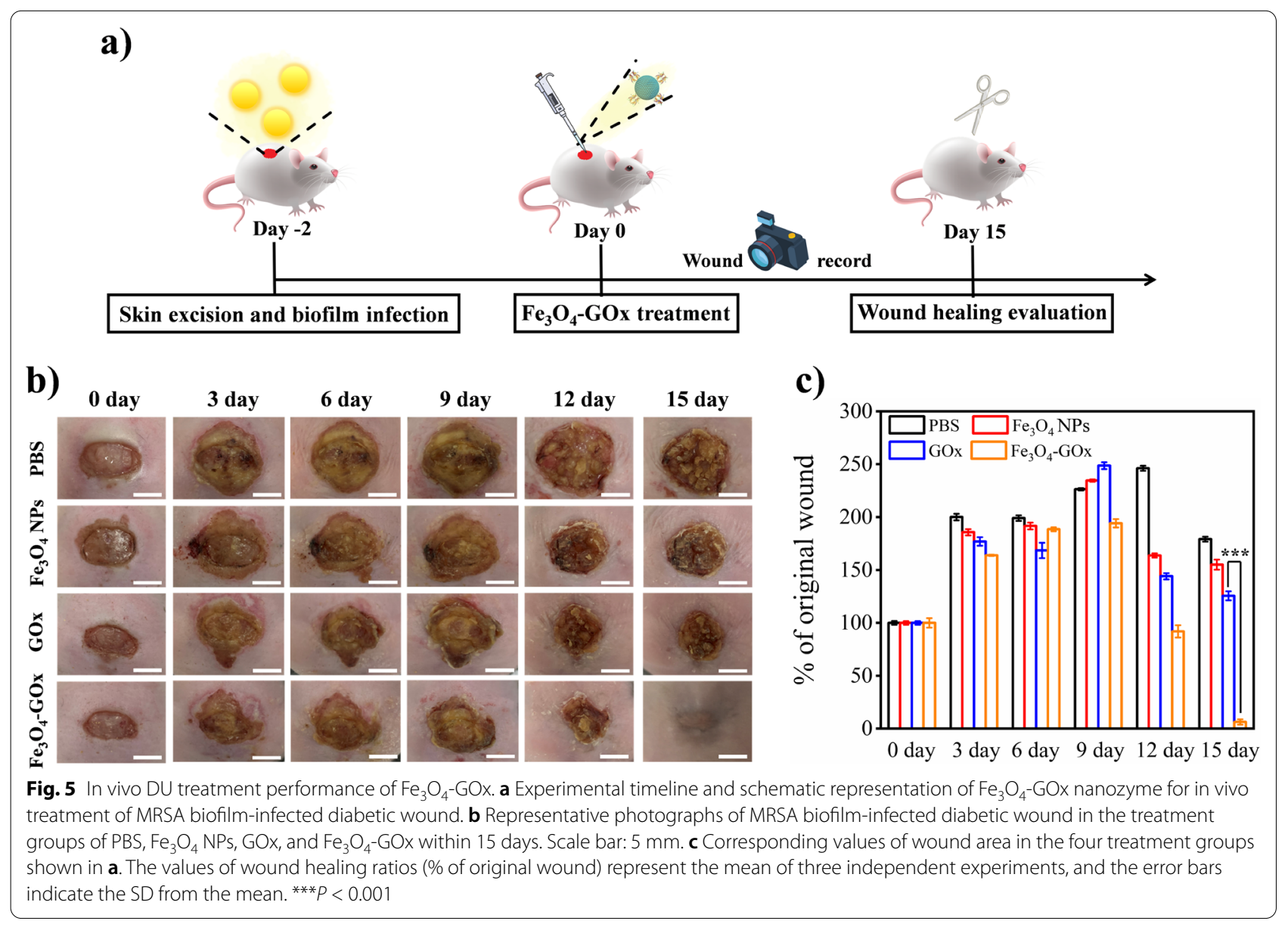


was accelerated in the other three treatment groups, and the $\mathrm{Fe}_{3} \mathrm{O}_{4}$-GOx nanozyme treatment group exhibited the fastest healing speed, indicating that both of the GOx and $\mathrm{Fe}_{3} \mathrm{O}_{4}$ NPs components of nanozyme contribute to the healing of infected diabetic wound. This result is consistent with our hypothesis that $\mathrm{Fe}_{3} \mathrm{O}_{4}$ - $\mathrm{GOx}$ nanozyme with closely co-localized $\mathrm{GOx}$ and $\mathrm{Fe}_{3} \mathrm{O}_{4}$ NPs can synergistically address the issues of hyperglycemia, hypoxia, oxidative stress and biofilm infection, reshaping the pathological wound microenvironment and rescuing the stalled healing in DU. Compared with photodynamic antimicrobial chemotherapy commonly used in chronic wound treatment [51], $\mathrm{Fe}_{3} \mathrm{O}_{4}$-GOx nanozyme exhibits comparable broad-spectrum antimicrobial performance as well as wound healing rate without the help of light irradiation, addressing the shortcomings of conventional phototherapy (e.g., limited light penetration depth, and wound hypoxia). Furthermore, apart from outstanding anti-oxidant activity similar to the commonly used anti-oxidant hydrogel [52], the $\mathrm{Fe}_{3} \mathrm{O}_{4}$-GOx also possessed additional $\mathrm{pH}-$ switchable antimicrobial capability, which makes it more suitable for DU wound treatment.
Subsequently, histological analysis of wound tissues in the four treatment groups was carried out. Similar to normal skin tissue (Additional file 1: Fig. S21), morphological features of blood vessels and hair follicles was observed in the infected diabetic wound tissue after 15 days of $\mathrm{Fe}_{3} \mathrm{O}_{4}$-GOx treatment, indicating the complete re-epithelialization of wound (Fig. 6a). In addition, gram-staining and bacterial culture of the wound tissues in the four treatment groups were performed to evaluate the performance of $\mathrm{Fe}_{3} \mathrm{O}_{4}$-GOx for in vivo biofilm eradication. As shown in Fig. 6b, c, bacterial load in wound tissues was positively correlated with the healing of wound, and complete biofilm elimination was only obtained in the treatment group of $\mathrm{Fe}_{3} \mathrm{O}_{4}$-GOx on the 15th day of treatment. This phenomenon means that the inflammation phase of wound healing in DU will be greatly shortened by the treatment of $\mathrm{Fe}_{3} \mathrm{O}_{4}$-GOx nanozyme to recover the normal orchestrated course of wound-healing cascades [53]. Furthermore, the collagen deposition as well as blood vessel density of wound tissues in the four treatment groups were investigated. It was found that $\mathrm{Fe}_{3} \mathrm{O}_{4}-\mathrm{GOx}$ treatment accelerated the collagen deposition (light blue color in Fig. 7a), fiber alignment (Additional file 1: Fig.

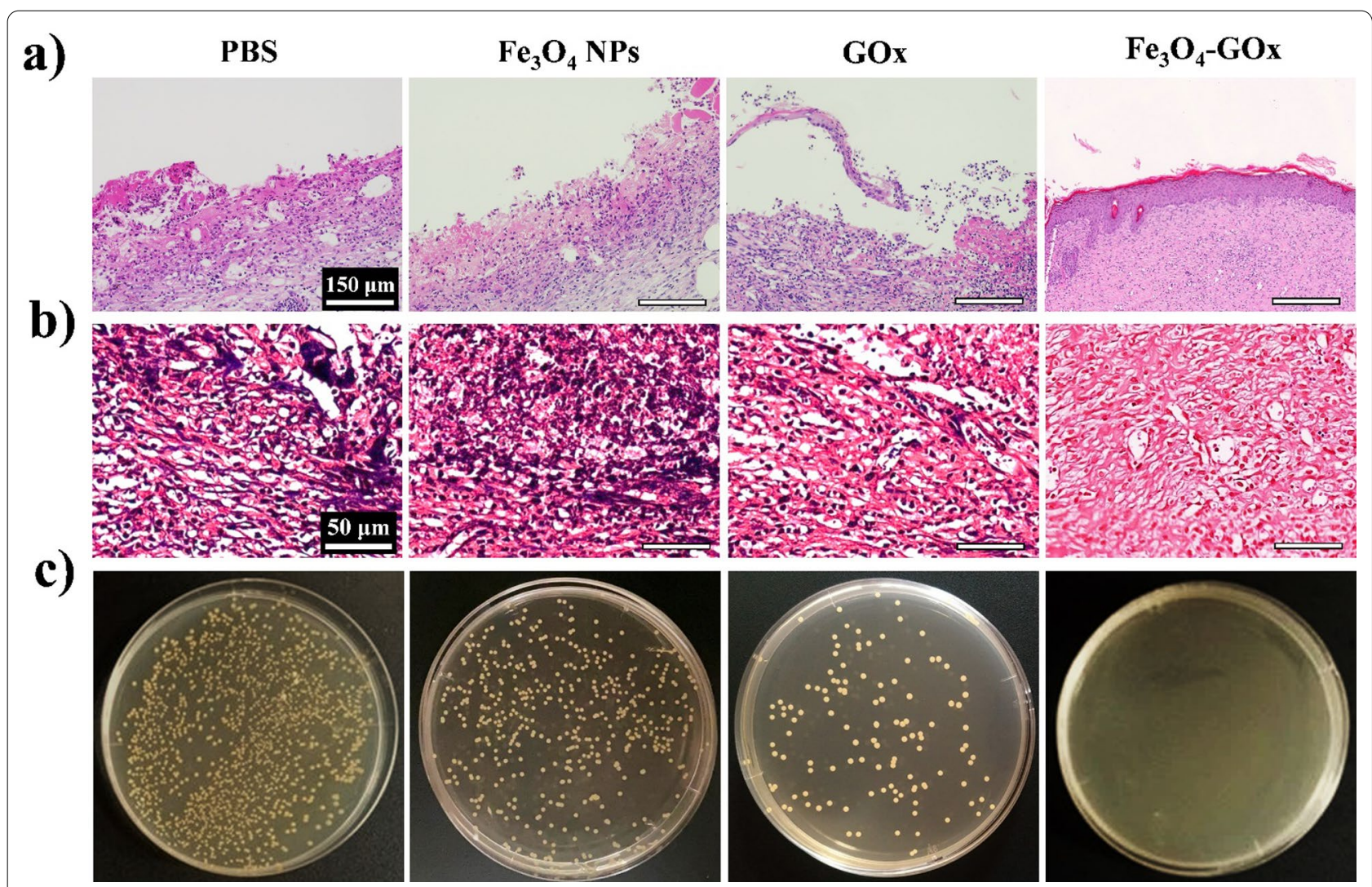

Fig. 6 Representative hematoxylin and eosin (HE) staining (a), gram-staining (b), and bacterial culture plate (c) images of MRSA biofilm-infected diabetic wound after 15 days treatment of $\mathrm{PBS}, \mathrm{Fe}_{3} \mathrm{O}_{4} \mathrm{NPS}$, $\mathrm{GOx}$, and $\mathrm{Fe}_{3} \mathrm{O}_{4}-\mathrm{GOx}$, respectively 
a)

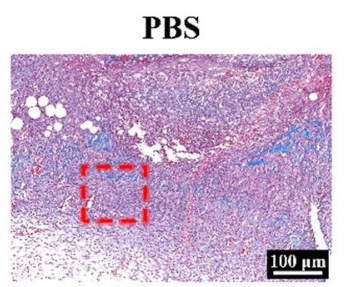

GOx

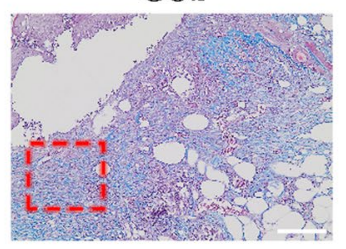

b)

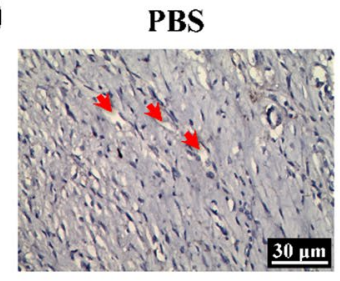

GOx

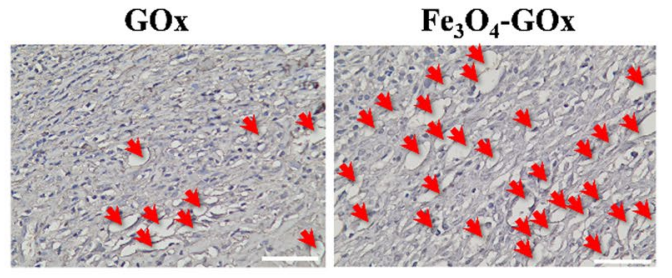

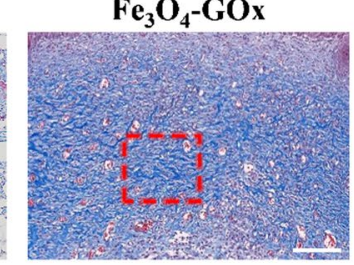

$\mathrm{Fe}_{3} \mathrm{O}_{4} \mathrm{NPs}$

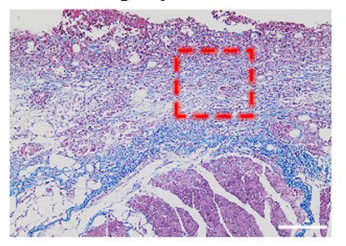

$\mathrm{Fe}_{3} \mathrm{O}_{4}-\mathrm{GOx}$

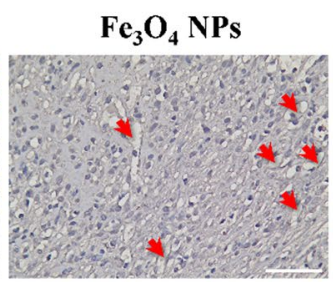

$\mathrm{Fe}_{3} \mathrm{O}_{4}-\mathrm{GOX}$
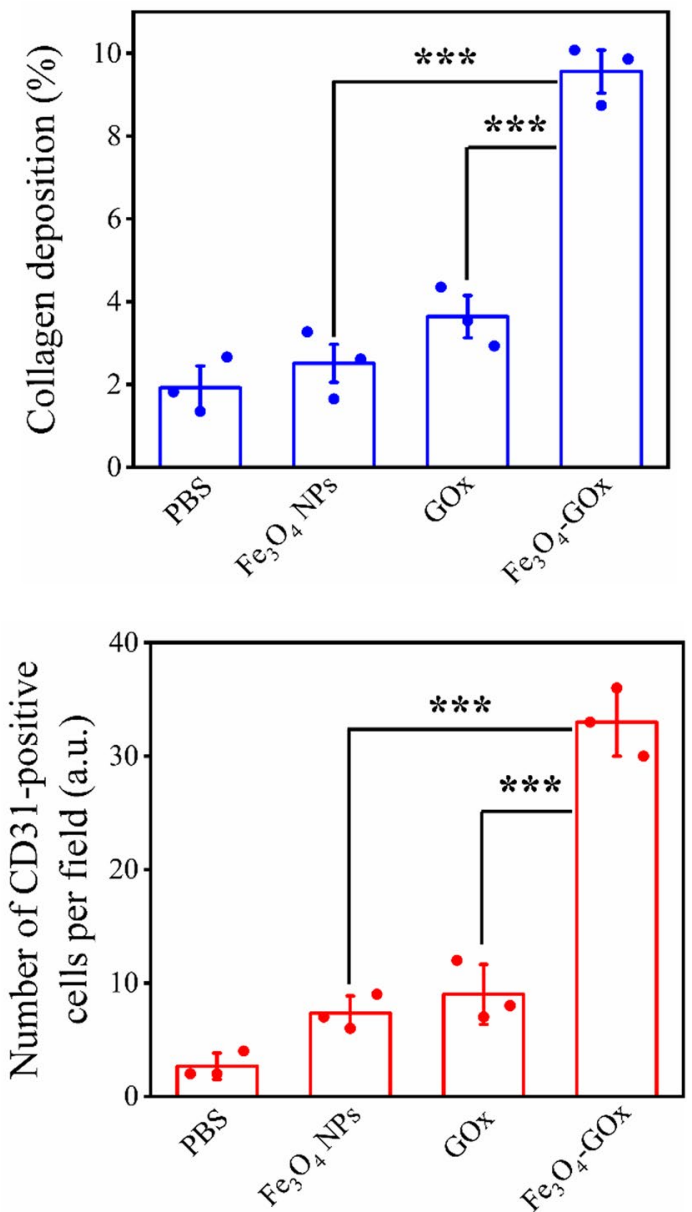

Fig. 7 Collagen deposition and blood vessel formation in DU wound under different treatment. a Representative Masson's trichrome staining images and the corresponding quantitative data of collagen deposition percentage of the tissues of MRSA biofilm-infected diabetic wound in four treatment groups. The red rectangle parts in the images are magnified in Additional file 1: Fig. S17 to show the condition of fiber alignment. b Representative CD31 staining images and the corresponding quantitative data of the CD34-positive cell's number of the tissues of MRSA biofilm-infected diabetic wound in four treatment groups indicate the condition of blood vessel formation. In $\mathbf{a}$ and $\mathbf{b}$, the values of collagen deposition percentage and CD31-positive cell's number determined using 9 staining images from three independent experiments are stated as mean $\pm S D$. ${ }^{* *} P<0.001$

S22), and blood vessel formation (red arrows in Fig. 7b) of wound tissues compared to the other three treatment groups based on Masson's trichrome and immunohistochemistry CD31 staining assays. The collagen deposition, fiber alignment and blood vessels formation of wound tissues on the 15th day of $\mathrm{Fe}_{3} \mathrm{O}_{4}$-GOx treatment was almost same to that of normal skin tissues (Additional file 1: Fig. S23), demonstrating that the $\mathrm{Fe}_{3} \mathrm{O}_{4}$-GOx nanozyme also has a notable accelerated effect on the proliferation and remodeling courses of wound healing besides shortening the inflammation phase [54]. These multi-dimensional experimental results describe above strongly prove the feasibility of $\mathrm{Fe}_{3} \mathrm{O}_{4}-\mathrm{GOx}$ nanozyme for in vivo DU treatment to rescue the stalled wound healing. In addition to the mice model of biofilm-infected diabetic wound, the in vivo performance of $\mathrm{Fe}_{3} \mathrm{O}_{4}$-GOx nanozyme for the healing of non-infected diabetic wound was further evaluated. As shown in Additional file 1: Fig. S24, compared with the control group (PBS), the $\mathrm{Fe}_{3} \mathrm{O}_{4}$ - $\mathrm{GOx}$ treated non-infected diabetic wounds healed completely on the 10th day of treatment. Moreover, the $\mathrm{Fe}_{3} \mathrm{O}_{4}$ - $\mathrm{GOx}$ was found to accelerate the collagen deposition, blood vessel formation, and tissue re-epithelization of noninfected diabetic wound based on the results of Masson's trichrome staining (Additional file 1: Fig. S25), CD 31 staining (Additional file 1: Fig. S26) and HE analysis 
(Additional file 1: Fig. S27). These results demonstrate that $\mathrm{Fe}_{3} \mathrm{O}_{4}$-GOx can greatly accelerate the healing of non-infected diabetic wound via the GOx/CAT cascade reaction, which means that the gluconic acid produced in the oxidation process of glucose has negligible effect on the in vivo performance of $\mathrm{Fe}_{3} \mathrm{O}_{4}$-GOx nanozyme.

The potential biotoxicity of nanomaterials is a key obstacle to its clinical transformation [55]. By considering the outstanding biocompatibility of the components of $\mathrm{Fe}_{3} \mathrm{O}_{4}$ NPs (an FDA-approved nanomaterial) and GOx (a natural protein), the $\mathrm{Fe}_{3} \mathrm{O}_{4}$-GOx nanozyme has predictable excellent biosafety in vitro and in vivo. By performing antiproliferation assay, HUVEC cells were found to possess high viability after incubation with $\mathrm{Fe}_{3} \mathrm{O}_{4}$ - $\mathrm{GOx}$ nanozyme, $\mathrm{Fe}_{3} \mathrm{O}_{4} \mathrm{NPs}$, and GOx respectively for different times, confirming their wonderful biocompatibility in vitro (Additional file 1: Fig. S28). To evaluate the biosafety effect of $\mathrm{Fe}_{3} \mathrm{O}_{4}$-GOx in vivo, healthy diabetic mice were subcutaneously injected with $\mathrm{Fe}_{3} \mathrm{O}_{4}$-GOx nanozyme, $\mathrm{Fe}_{3} \mathrm{O}_{4} \mathrm{NPs}$, GOx, and PBS (control), respectively, and the blood biochemical assay as well as organ histopathological analysis was carried out on the 7th day of injection. As summarized in Additional file 1: Fig. S29, no obvious difference of blood biochemical indicators detected was found in the four groups of injection, indicating the negligible damage of $\mathrm{Fe}_{3} \mathrm{O}_{4}$-GOx to the metabolism of liver and kidney of mice. Moreover, no lesions and inflammation were found in the main organs of the mice treated by $\mathrm{Fe}_{3} \mathrm{O}_{4}$-GOx compared to the control from the histopathological staining images, exhibiting outstanding in vivo biocompatibility (Additional file 1: Fig. S30). This confirmed excellent in vitro and in vivo biosafety of $\mathrm{Fe}_{3} \mathrm{O}_{4}$-GOx nanozyme lay a solid foundation for its future clinical transformation.

\section{Conclusions}

In summary, we report a PNCC strategy for spatialtemporal modulation of pathological wound microenvironment to rescue stalled healing in DU by employing $\mathrm{Fe}_{3} \mathrm{O}_{4}$-GOx nanozyme. The $\mathrm{Fe}_{3} \mathrm{O}_{4}$-GOx possesses $\mathrm{GOx}$, $\mathrm{CAT}$ and POD activities, and can program $\mathrm{pH}$-switchable GOx/POD and GOx/CAT cascade reaction in neutral and acidic condition, respectively. The GOx/POD cascade reaction generating consecutive fluxes of toxic hydroxyl radical spatially targets the acidic biofilm $(\mathrm{pH} \sim$ 5.5), and eradicates biofilm to shorten the inflammatory phase and initiate the normal healing course. Furthermore, the GOx/CAT cascade reaction producing consecutive fluxes of oxygen spatially targets the neutral wound tissue, and accelerates the proliferation and remodeling phases of wound healing by addressing the issues of hyperglycemia, hypoxia, and excessive oxidative stress. Notably, the shortened inflammatory phase temporally coupled with accelerated proliferation and remodeling phases significantly speed up the normal orchestrated wound-healing cascades, enables complete in vivo re-epithelialization of biofilm-infected diabetic wound within 15 days, demonstrating strong capability for in vivo DU management. More importantly, inheriting the excellent biocompatibility from the $\mathrm{GOx}$ and clinically approved $\mathrm{Fe}_{3} \mathrm{O}_{4}$ NPs, the $\mathrm{Fe}_{3} \mathrm{O}_{4}$-GOx nanozyme exerts great potential for clinical transformation. We believe that the proposed PNCC concept offers a new perspective for complex pathological microenvironment remodeling, and may provide a powerful modality for the treatment of pathological microenvironment-associated diseases.

\section{Materials and methods} Chemicals and materials

Iron (III) chloride hexahydrate $\left(\mathrm{FeCl}_{3} \cdot 6 \mathrm{H}_{2} \mathrm{O}\right)$, sodium oleate, oleic acid, 1-octadecene, poly (allylamine hydrochloride) (PAH; $\left.M_{\mathrm{w}}=15,000 \mathrm{Da}\right)$, phosphate buffered saline (PBS), tetramethylammonium hydroxide, $N$-(3-(dimethylamino)propyl- $N^{\prime}$-ethylcarbodiimide) hydrochloride (EDC), $\quad N$-hydroxysulfosuccinimide sodium salt (NHS), 3-(4,5-dimethyl-2-thiazolyl)-2,5-diphenyl-2 H-tetrazolium bromide (MTT) assay kit and 2',7'-dichlorohydrofluorescein diacetate (DCFH; $\geq 94 \%$ ), glucose oxidase (GOx) were purchased from Sigma-Aldrich. 3,3',5,5' -tetramethylbenzidine (TMB), 2,2'-azinobis (3-ethylbenzothiazoline-6-sulfonic acid) diammonium salt (ABTS), o-phenylenediamine (OPD; 98\%), methylene blue (MB), terephthalic acid (TA) and hydrogen peroxide $\left(\mathrm{H}_{2} \mathrm{O}_{2}\right)$ assay kit were obtained from Beyotime Biotechnology. Bicinchoninic acid (BCA) protein assay kit, malondialdehyde (MDA) and protein carbonyl assay kit were obtained from Nanjing Jiancheng Institute of Biological Engineering. Live/dead bacteria viability kit was purchased from Thermo Fisher Scientific. All other chemicals were obtained from Adamasbeta and used without further purification. Deionized (DI) water (Millipore Milli-Q grade, 18.2 M $\Omega$ ) was used in all the experiments.

\section{Preparation of $\mathrm{Fe}_{3} \mathrm{O}_{4}-\mathrm{GOx}$ nanozyme}

Magnetic $\mathrm{Fe}_{3} \mathrm{O}_{4}$ NPs were first synthesized by thermal decomposition of the iron-oleate complex according to previously reported methods [38, 39]. Briefly, $12.2 \mathrm{~g}$ of sodium oleate and $3.6 \mathrm{~g}$ of $\mathrm{FeCl}_{3} \cdot 6 \mathrm{H}_{2} \mathrm{O}$ were dissolved in the mixed solution of DI water, hexane and absolute ethanol, and refluxed at $70{ }^{\circ} \mathrm{C}$ for $4 \mathrm{~h}$. Then, the upper organic liquid obtained by the liquid separation was washed with DI water, and hexane was removed to obtain a brown-red iron oleate complex. Next, $6 \mathrm{~g}$ of iron oleate complex was dissolved in octadecene and oleic acid mixed solution under the protection of $\mathrm{N}_{2}$. The mixture was then heated 
to $320{ }^{\circ} \mathrm{C}$, refluxed and condensed for $30 \mathrm{~min}$ to obtain magnetic $\mathrm{Fe}_{3} \mathrm{O}_{4}$ NPs. In order to make the prepared $\mathrm{Fe}_{3} \mathrm{O}_{4}$ NPs water-soluble, absolute ethanol was added to $\mathrm{Fe}_{3} \mathrm{O}_{4}$ NPs dispersed in hexane followed by magnet separation, and tetramethylammonium hydroxide and propanol were subsequently added. After 5 min shaking, the mixture was separated by magnet, and water-soluble $\mathrm{Fe}_{3} \mathrm{O}_{4}$ NPs was obtained by acetone wash and finally dispersed in DI water.

To prepare $\mathrm{Fe}_{3} \mathrm{O}_{4}$-GOx nanozyme, cationic $\mathrm{PAH}$ polyelectrolyte was first used to coat the negatively charged $\mathrm{Fe}_{3} \mathrm{O}_{4} \mathrm{NPs}$, and the carboxyl group of GOx molecules was sequentially conjugated with the amino group of PAH through a chemical covalent coupling method [56, 57]. In brief, $0.1 \mathrm{~g}$ of $\mathrm{PAH}$ was dissolved in $10 \mathrm{~mL}$ of $\mathrm{NaCl}$ solution $(1 \mathrm{mM})$, and $1 \mathrm{~mL}$ of as-prepared $\mathrm{Fe}_{3} \mathrm{O}_{4}$ NPs were added. The mixture was stirred at $900 \mathrm{rpm}$ for $3 \mathrm{~h}$ at room temperature, and the $\mathrm{PAH}$-coated $\mathrm{Fe}_{3} \mathrm{O}_{4}$ NPs $\left(\mathrm{Fe}_{3} \mathrm{O}_{4} / \mathrm{PAH}\right)$ were collected by centrifugation at $12,000 \mathrm{rpm}$ for $15 \mathrm{~min}$ and dispersed in $1 \mathrm{~mL}$ of DI water for GOx modification. First, $4.1 \mathrm{mg}$ EDC and $4.5 \mathrm{mg}$ NHS were added to $1 \mathrm{~mL}$ of $10 \mathrm{mg} / \mathrm{mL}$ GOx to activate the carboxyl group. After $30 \mathrm{~min}, 1 \mathrm{~mL}$ of $\mathrm{Fe}_{3} \mathrm{O}_{4} / \mathrm{PAH}$ were added to the mixture, and stirred at $900 \mathrm{rpm}$ for $24 \mathrm{~h}$ at room temperature. After the reaction was completed, the mixture was centrifuged at $12,000 \mathrm{rpm}$ for $15 \mathrm{~min}$, and the precipitate $\left(\mathrm{Fe}_{3} \mathrm{O}_{4}\right.$-GOx nanozyme) was washed with DI water, and finally resuspended in DI water for further characterization and application.

\section{In vitro biocompatibility assay}

The biocompatibility of $\mathrm{Fe}_{3} \mathrm{O}_{4}$-GOx nanozyme was determined by MTT assay using human umbilical vein endothelial cells (HUVEC). In brief, HUVEC cells were seeded into a 96-well plate (8000-10,000 cells/well) and cultured overnight. Then the cells were treated with $\mathrm{Fe}_{3} \mathrm{O}_{4}$-GOx nanozyme with different concentrations $(0$, $5,10,50,100$, and $200 \mu \mathrm{g} / \mathrm{mL}$ of iron element). After $24 \mathrm{~h}$ of culture, MTT reagent was added and the cell viability was evaluated with a microplate reader.

\section{$\mathrm{pH}$-switchable cascade catalysis performance of $\mathrm{Fe}_{3} \mathrm{O}_{4}-\mathrm{GOx}$ nanozyme}

The GOx activity (oxidize glucose to produce $\mathrm{H}_{2} \mathrm{O}_{2}$ ) of $\mathrm{Fe}_{3} \mathrm{O}_{4}$-GOx nanozyme was evaluated by glucose depletion and $\mathrm{H}_{2} \mathrm{O}_{2}$ generation. For glucose depletion assay, $\mathrm{Fe}_{3} \mathrm{O}_{4}$-GOx nanozymes with different concentrations (0, $5,10,20,50,100$, and $200 \mu \mathrm{g} / \mathrm{mL}$ of iron element) were incubated with diabetic blood sample containing around $20 \mathrm{mM}$ glucose for $5 \mathrm{~min}$, and the blood glucose concentration was measured with a glucometer. For $\mathrm{H}_{2} \mathrm{O}_{2}$ generation assay, $\mathrm{Fe}_{3} \mathrm{O}_{4}$-GOx nanozymes with different concentrations $(0,5,10,20,50,100$, and $200 \mu \mathrm{g} / \mathrm{mL}$ of iron element) were incubated with $20 \mathrm{mM}$ glucose solution for different times $(5,10,30,60,90,120$ and $240 \mathrm{~min})$. Then the mixtures were incubated with $\mathrm{H}_{2} \mathrm{O}_{2}$ detecting reagent for $30 \mathrm{~min}$, and the amount of $\mathrm{H}_{2} \mathrm{O}_{2}$ generated was determined by measuring the absorbance of the mixture at a wavelength of $560 \mathrm{~nm}$.

The CAT activity of $\mathrm{Fe}_{3} \mathrm{O}_{4}$-GOx nanozyme and the occurrence of coupled GOx/CAT cascade reaction was evaluated by demonstrating the generation of oxygen in the system of $\mathrm{Fe}_{3} \mathrm{O}_{4}$-GOx/glucose. Briefly, $\mathrm{Fe}_{3} \mathrm{O}_{4}$-GOx nanozymes $(200 \mu \mathrm{g} / \mathrm{mL}$ of iron element) was co-cultured with glucose solution $(20 \mathrm{mM})$ for 5 min under different $\mathrm{pH}$ conditions $(5.5,6.5,7.5$ and 8.5$)$, and oxygen probes (JPBJ-608 portable Dissolved Oxygen Meters, Shanghai REX Instrument Factory) was used to detect the amount of oxygen generated in the mixture.

The POD activity of $\mathrm{Fe}_{3} \mathrm{O}_{4}$-GOx nanozyme and the occurrence of coupled GOx/POD cascade reaction was assessed by the oxidation of POD substrates of TMB, ABTS and OPD respectively, in the system of $\mathrm{Fe}_{3} \mathrm{O}_{4}$-GOx/glucose. Briefly, $\mathrm{Fe}_{3} \mathrm{O}_{4}$-GOx nanozymes $(200 \mu \mathrm{g} / \mathrm{mL}$ of iron element) was co-cultured with glucose solution $(20 \mathrm{mM})$ for $5 \mathrm{~min}$, and POD substrate (TMB, ABTS or OPD) was then added and incubated for 30 min under different $\mathrm{pH}$ conditions $(5.5,6.5,7.5$ and 8.5). The oxidation of TMB (using sulfuric acid as a stop reagent), ABTS, and OPD was evaluated by measuring the absorbance of the mixture at the wavelength of 450 , 734 , and $492 \mathrm{~nm}$, respectively.

\section{Measurement of hydroxyl radical}

MB degradation and TA fluorescent assay were employed to assess the ability of $\mathrm{Fe}_{3} \mathrm{O}_{4}$-GOx nanozyme to generate .OH after incubation with glucose. $\mathrm{MB}$ can be degraded by $\cdot \mathrm{OH}$ to generate $\mathrm{MB}-\mathrm{OH}$, while $\mathrm{TA}$ can react with . $\mathrm{OH}$ to generate fluorescent $\mathrm{TAOH}$. In typical experiments, $\mathrm{Fe}_{3} \mathrm{O}_{4}$-GOx nanozymes $(200 \mu \mathrm{g} / \mathrm{mL}$ of iron element) was co-cultured with glucose solution $(20 \mathrm{mM})$ for $5 \mathrm{~min}$, then $\mathrm{MB}$ degradation and TA fluorescent assay were performed respectively. In $\mathrm{MB}$ degradation, the mixture of $\mathrm{Fe}_{3} \mathrm{O}_{4}$ - $\mathrm{GOx}$ nanozyme and glucose was incubated with $\mathrm{MB}(10 \mu \mathrm{g} / \mathrm{mL})$ for $24 \mathrm{~h}$, and the absorbance of the mixture at the wavelength of $664 \mathrm{~nm}$ was recorded. In TA fluorescent assay, the mixture of $\mathrm{Fe}_{3} \mathrm{O}_{4}$-GOx nanozyme and glucose was incubated with TA $(0.5 \mathrm{mM})$ for $12 \mathrm{~h}$, and the fluorescence spectrum of the mixture was measured.

\section{Bacteria culture and antimicrobial experiments}

Methicillin-resistant Staphylococcus aureus (MRSA) (ATCC 33591) and Escherichia coli (E. coli) (ATCC 8739) were used in our experiments. MRSA and E. coli were cultured in tryptic soy broth (TSB) medium and lysogeny 
broth (LB) medium, respectively, and harvested at the exponential growth phase before use. For antimicrobial experiments, $10^{6} \mathrm{CFU}$ of bacteria were incubated with the mixture of $\mathrm{Fe}_{3} \mathrm{O}_{4}$-GOx nanozyme $(200 \mu \mathrm{g} / \mathrm{mL}$ of iron element) and glucose $(20 \mathrm{mM})$ for $2 \mathrm{~h}$ in the condition of $\mathrm{pH} 6.5$, and the antimicrobial performance was evaluated by the live/dead bacterial staining assay and SEM-based bacterial morphology investigation.

\section{Live/dead bacterial staining assay}

Live/dead staining assay kit was used to evaluate the viability of bacteria. In brief, the bacteria before and after $\mathrm{Fe}_{3} \mathrm{O}_{4}$-GOx nanozyme treatment were mixed with the dye solution containing SYTO 9 and propidium iodide for $30 \mathrm{~min}$ in the dark, and then imaged with a confocal fluorescence microscope. Live bacteria were stained by SYTO 9 with green color, while dead bacteria were stained by propidium iodide with red color due to the damage of cell membrane and wall [58].

\section{SEM-based morphological study of bacteria}

The morphology of bacteria was characterized by fieldemission scanning electron microscopy (FESEM). In brief, the bacteria before and after $\mathrm{Fe}_{3} \mathrm{O}_{4}$-GOx nanozyme treatment were fixed with glutaraldehyde $(2.5 \%)$ in the dark for $2 \mathrm{~h}$, and dehydrated by ethanol solution with different concentrations (50\%, 70\%, 90\% and 100\%) for $10 \mathrm{~min}$. The dehydrated bacterial samples were dropped on silicon wafer, and imaged with FESEM after nitrogen drying and platinum coating.

\section{Mice model of DU}

Type II diabetic mice (db/db, 6 weeks, $\sim 40$ g) were purchased from the Nanjing Si Ke Rui Biological Technology Co., Ltd., and allowed to acclimatize for 1 week in the laboratory. All animal experiments were carried out in compliance with the protocols approved by the Shandong University Laboratory Animal Center. To construct the mouse model of DU, the diabetic mouse was firs anesthetized, and an oval wound $(12 \mathrm{~mm}$ in long axis, $9 \mathrm{~mm}$ in short axis) was created on the back of mouse using disposable biopsy punch followed by bacteria $\left(10^{7} \mathrm{CFU}\right.$ of $E$. coli or MRSA) inoculation for 2 days before treatment to form biofilm in situ.

\section{In vivo DU treatment}

The MRSA biofilm-infected wound of diabetic mice were divided into four treatment groups including $\mathrm{Fe}_{3} \mathrm{O}_{4}$-GOx, $\mathrm{Fe}_{3} \mathrm{O}_{4}$ NPs, GOx and PBS, and each treatment group contained 5 mice. To carry out in vivo DU treatment, materials $\left(\mathrm{Fe}_{3} \mathrm{O}_{4}\right.$ - $\mathrm{GOx}, \mathrm{Fe}_{3} \mathrm{O}_{4} \mathrm{NPs}, \mathrm{GOx}$ or PBS) were added onto the infected diabetic wound, and pictures of the wound were taken every day to record their festered areas. After
15 days treatment, the mice were executed and the skin tissues at the wound sites were dissected. A variety of experimental methods including bacteria culture, hematoxylin and eosin (HE) staining, Masson's trichrome staining, gram staining and CD31 immunohistochemistry staining, were performed to evaluate the actual therapeutic ability of $\mathrm{Fe}_{3} \mathrm{O}_{4}$-GOx nanozyme for in vivo DU treatment.

\section{Supplementary Information}

The online version contains supplementary material available at https://doi. org/10.1186/s12951-021-01215-6.

Additional file 1. Additional experimental methods and figures.

\section{Acknowledgements}

This work was supported by the National Natural Science Foundation of China (31500802, 21628201), the Natural Science Foundation of Jiangsu Province (BK20190097), the Natural Science Foundation of Shandong Province (ZR2020MB074) and the Program of Qilu Young Scholars of Shandong University. This work was also supported by the Taishan Scholars Program for Young Expert of Shandong Province (tsqn201909021), and the Youth cross-scientific innovation group of Shandong University.

\section{Authors' contributions}

$X D$ and $B J$ contributed equally to this work. $Y Y$ and $Y-Q L$ designed the project and conceived the manuscript. XD and BJ performed most of the experiments and analyzed the results. CZ assisted in performing in vivo experiments. WW designed scheme and assisted in preparing figures in the manuscript. $\mathrm{XL}$ and YQ assisted in data analysis. MZ and WL assisted in manuscript writing. All authors read and approved the final manuscript.

Availability of data and materials

All data generated or analyzed during this study are included in this published article.

\section{Declarations}

Ethics approval and consent to participate

All animal experiments were carried out in compliance with the protocols approved by the Shandong University Laboratory Animal Center.

\section{Consent for publication}

All authors have provided consent for the manuscript to be published.

\section{Competing interests}

The authors declare that they have no competing interests.

\section{Author details}

${ }^{1}$ Institute of Advanced Interdisciplinary Science, School of Physics, Shandong University, Jinan 250100, China. ${ }^{2}$ Laboratory Animal Center of Shandong University, Jinan 250012, China. ${ }^{3}$ College of Chemistry, Chemical Engineering and Materials Science, Collaborative Innovation Center of Functionalized Probes for Chemical Imaging in Universities of Shandong, Key Laboratory of Molecular and Nano Probes, Ministry of Education, Shandong Normal University, Jinan 250014, China. ${ }^{4}$ Suzhou Research Institute, Shandong University, Suzhou 215123, China.

Received: 26 October 2021 Accepted: 16 December 2021

Published online: 04 January 2022 


\section{References}

1. Cho NH, Shaw JE, Karuranga S, Huang Y, Fernandes JDD, Ohlrogge AW, Malanda B. IDF Diabetes Atlas: global estimates of diabetes prevalence for 2017 and projections for 2045. Diabetes Res Clin Pract. 2018;138:271-81.

2. Armstrong DG, Boulton AJM, Bus SA. Diabetic foot ulcers and their recurrence. N Engl J Med. 2017;376:2367-75.

3. Khazaeli P, Alaei M, Khaksarihadad M, Ranjbar M. Preparation of PLA chitosan nanoscaffolds containing cod liver oil and experimental diabetic wound healing in male rats study. J Nanobiotechnol. 2020;18:176.

4. Moulik PK, Mtonga R, Gill GV. Amputation and mortality in new-onset diabetic foot ulcers stratified by etiology. Diabetes Care. 2003;26:491-4.

5. Jeffcoate WJ, Vileikyte L, Boyko EJ, Armstrong DG, Boulton AJM. Current challenges and opportunities in the prevention and management of diabetic foot ulcers. Diabetes Care. 2018:41:645-52.

6. Ouyang J, Ji X, Zhang X, Feng C, Tang Z, Kong N, Xie A, Wang J, Sui X, Deng L, Liu Y, Kim JS, Cao Y, Tao W. In situ sprayed NIR-responsive, analgesic black phosphorus-based gel for diabetic ulcer treatment. Proc Natl Acad Sci USA. 2020:117:28667.

7. Wolcott RD, Rhoads DD, Dowd SE. Biofilms and chronic wound inflammation. J Wound Care. 2008;17:333-41.

8. Wang J, Wu H, Peng Y, Zhao Y, Qin Y, Zhang Y, Xiao Z. Hypoxia adipose stem cell-derived exosomes promote high-quality healing of diabetic wound involves activation of PI3K/Akt pathways. J Nanobiotechnol. 2021;19:202.

9. Thangarajah H, Yao D, Chang El, Shi Y, Jazayeri L, Vial IN, Galiano RD, Du XL, Grogan R, Galvez MG, Januszyk M, Brownlee M, Gurtner GC. The molecular basis for impaired hypoxia-induced VEGF expression in diabetic tissues. Proc Natl Acad Sci USA. 2020;106:13505-10.

10. Liu Y, Shi J. Antioxidative nanomaterials and biomedical applications. Nano Today. 2019;27:146-77.

11. Zhao X, Shi A, Ma Q, Yan X, Bian L, Zhang P, Wu J. Nanoparticles prepared from pterostilbene reduce blood glucose and improve diabetes complications. J Nanobiotechnol. 2021:19:191.

12. Chen H, Cheng Y, Tian J, Yang P, Zhang X, Chen Y, Hu Y, Wu J. Dissolved oxygen from microalgae-gel patch promotes chronic wound healing in diabetes. Sci Adv. 2020:6:eaba4311.

13. Hayes PD, Alzuhir N, Curran G, Loftus IM. Topical oxygen therapy promotes the healing of chronic diabetic foot ulcers: a pilot study. J Wound Care. 2017;26:652-60.

14. Wang J, Chen XY, Zhao Y, Yang Y, Wang W, Wu C, Yang B, Zhang Z, Zhang L, Liu Y, Du X, Li W, Qiu L, Jiang P, Mou XZ, Li YQ. pH-switchable antimicrobial nanofiber networks of hydrogel eradicate biofilm and rescue stalled healing in chronic wounds. ACS Nano. 2019;13:11686-97.

15. Li X, Huang W, Zheng X, Chang S, Li C, Cheng Q, Zhu S. Synergistic in vitro effects of indocyanine green and ethylenediamine tetraacetate-mediated antimicrobial photodynamic therapy combined with antibiotics for resistant bacterial biofilms in diabetic foot infection. Photodiagn Photodyn Ther. 2019;25:300-8

16. Wu H, Li F, Shao W, Gao J, Ling D. Promoting angiogenesis in oxidative diabetic wound microenvironment using a nanozyme-reinforced selfprotecting hydrogel. ACS Cent Sci. 2019;5:477-85.

17. Wang T, Li Y, Cornel EJ, Li C, Du J. Combined antioxidant-antibiotic treatment for effectively healing infected diabetic wounds based on polymer vesicles. ACS Nano. 2021;15:9027-38.

18. Zhao H, Huang J, Li Y, Lv X, Zhou H, Wang H, Xu Y, Wang C, Wang J, Liu Z. ROS-scavenging hydrogel to promote healing of bacteria infected diabetic wounds. Biomaterials. 2020;258:120286.

19. Qu Q, Zhang S, Fu C, Yu L, Xin P, Gu Z, Cao Z, Wu J, Wang Y. More natural more better: triple natural anti-oxidant puerarin/ferulic acid/polydopamine incorporated hydrogel for wound healing. J Nanobiotechnol. 2021;19:237.

20. Zhang J, Xiao C, Zhang X, Lin Y, Yang H, Zhang Y, Ding J. An oxidative stress-responsive electrospun polyester membrane capable of releasing anti-bacterial and anti-inflammatory agents for postoperative anti-adhesion. J Control Release. 2021;335:359-68.

21. Feng X, Li J, Zhang X, Liu T, Ding J, Chen X. Electrospun polymer micro/ nanofibers as pharmaceutical repositories for healthcare. J Control Release. 2019;302:19-41.

22. Ding J, Zhang J, Li J, Li D, Xiao C, Xiao H, Yang H, Zhuang X, Chen X. Electrospun polymer biomaterials. Prog Polym Sci. 2019;90:1-34.
23. Wang S, Zheng H, Zhou L, Cheng F, Liu Z, Zhang H, Wang L, Zhang Q. Nanoenzyme-reinforced injectable hydrogel for healing diabetic wounds infected with multidrug resistant bacteria. Nano Lett. 2020;20:5149-58.

24. Shiekh PA, Singh A, Kumar A. Exosome laden oxygen releasing antioxidant and antibacterial cryogel wound dressing OxOBand alleviate diabetic and infectious wound healing. Biomaterials. 2020;249:120020.

25. Masood N, Ahmed R, Tariq M, Ahmed Z, Masoud MS, Ali I, Asghar R, Andleeb A, Hasan A. Silver nanoparticle impregnated chitosan-PEG hydrogel enhances wound healing in diabetes induced rabbits. Int J Pharm. 2019;559:23-36.

26. Lan Q, Lu R, Chen H, Pang Y, Xiong F, Shen C, Qin Z, Zheng L, Xu G, Zhao J. MMP-13 enzyme and $\mathrm{pH}$ responsive theranostic nanoplatform for osteoarthritis. J Nanobiotechnol. 2020;18:117.

27. Liu Y, Cheng Y, Zhang H, Zhou M, Yu Y, Lin S, Jiang B, Zhao X, Miao L, Wei CW, Liu Q, Lin YW, Du Y, Butch CJ, Wei H. Integrated cascade nanozyme catalyzes in vivo ROS scavenging for anti-inflammatory therapy. Sci Adv. 2020;6:eabb2695

28. Liu Y, Du J, Yan M, Lau MY, Hu J, Han H, Yang OO, Liang S, Wei W, Wang H. Li J, Zhu X, Shi L, Chen W, Ji C, Lu Y. Biomimetic enzyme nanocomplexes and their use as antidotes and preventive measures for alcohol intoxication. Nat Nanotechnol. 2013;8:187-92.

29. Cai X, Jiao L, Yan H, Wu Y, Gu W, Du D, Lin Y, Zhu C. Nanozyme-involved biomimetic cascade catalysis for biomedical applications. Mater Today. 2020:44:211-28.

30. Wang Z, Dong K, Liu Z, Zhang Y, Chen Z, Sun H, Ren J, Qu X. Activation of biologically relevant levels of reactive oxygen species by Au/g-C3N4 hybrid nanozyme for bacteria killing and wound disinfection. Biomaterials. 2017;113:145-57.

31. Alizadeh N, Salimi A. Multienzymes activity of metals and metal oxide nanomaterials: applications from biotechnology to medicine and environmental engineering. J Nanobiotechnol. 2021;19:26.

32. Wang M, Chang M, Chen Q, Wang D, Li C, Hou Z, Lin J, Jin D, Xing B. Au2Pt-PEG-Ce6 nanoformulation with dual nanozyme activities for synergistic chemodynamic therapy/phototherapy. Biomaterials. 2020:252:120093.

33. Jiang D, Ni D, Rosenkrans ZT, Huang P, Yan X, Cai W. Nanozyme: new horizons for responsive biomedical applications. Chem Soc Rev. 2019:48:3683-704.

34. Fu LH, Qi C, Hu YR, Lin J, Huang P. Glucose oxidase-instructed multimodal synergistic cancer therapy. Adv Mater. 2019;31:1808325.

35. Gao L, Fan K, Yan X. Iron oxide nanozyme: a multifunctional enzyme mimetic for biomedical applications. Theranostics. 2017:7:3207-27.

36. Chen Z, Yin JJ, Zhou YT, Zhang Y, Song L, Song M, Hu S, Gu N. Dual enzyme-like activities of iron oxide nanoparticles and their implication for diminishing cytotoxicity. ACS Nano. 2012;6:4001-12.

37. Wang H, Wan K, Shi X. Recent advances in nanozyme research. Adv Mater 2019;31:1805368.

38. Wang J, Wu H, Yang Y, Yan R, Zhao Y, Wang Y, Chen A, Shao S, Jiang P, Li YQ Bacterial species-identifiable magnetic nanosystems for early sepsis diagnosis and extracorporeal photodynamic blood disinfection. Nanoscale. 2018:10:132-41.

39. Mou XZ, Chen XY, Wang J, Zhang Z, Yang Y, Shou ZX, Tu YX, Du X, Wu C, Zhao Y, Qin L, Jiang P, Chen C, Huang DS, Li YQ. Bacteria-instructed click chemistry between functionalized gold nanoparticles for point-of-care microbial detection. ACS Appl Mater Interfaces. 2019;11:23093-101.

40. Zou Y, Ito S, Yoshino F, Suzuki Y, Zhao L, Komatsu N. Polyglycerol grafting shields nanoparticles from protein corona formation to avoid macrophage uptake. ACS Nano. 2020;14:7216-26.

41. Shi Y, Wang J, Liu J, Lin G, Xie F, Pang X, Pei Y, Cheng Y, Zhang Y, Lin Z, Yin Z, Wang X, Niu G, Chen X, Liu G. Oxidative stress-driven DR5 upregulation restores TRAIL/Apo2L sensitivity induced by iron oxide nanoparticles in colorectal cancer. Biomaterials. 2020;233:119753.

42. Tao Y, Ju E, Ren J, Qu X. Bifunctionalized mesoporous silica-supported gold nanoparticles: intrinsic oxidase and peroxidase catalytic activities for antibacterial applications. Adv Mater. 2015;27:1097-104.

43. Wei $\mathrm{H}$, Wang $\mathrm{E}$. $\mathrm{Fe}_{3} \mathrm{O}_{4}$ magnetic nanoparticles as peroxidase mimetics and their applications in $\mathrm{H}_{2} \mathrm{O}_{2}$ and glucose detection. Anal Chem. 2008:80:2250-4.

44. Cai T, Fang G, Tian X, Yin JJ, Chen C, Ge C. Optimization of antibacterial efficacy of noble-metal-based core-shell nanostructures and effect of natural organic matter. ACS Nano. 2019;13:12694-702. 
45. Ma B, Wang S, Liu F, Zhang S, Duan J, Li Z, Kong Y, Sang Y, Liu H, Bu W, Li L. Self-assembled copper amino acid nanoparticles for in situ glutathione "AND" $\mathrm{H}_{2} \mathrm{O}_{2}$ sequentially triggered chemodynamic therapy. J Am Chem Soc. 2019;141:849-57.

46. Wu R, Chong Y, Fang G, Jiang X, Pan Y, Chen C, Yin JJ, Ge C. Synthesis of Pt hollow nanodendrites with enhanced peroxidase-like activity against bacterial infections: implication for wound healing. Adv Funct Mater. 2018;28:1801484.

47. Ninan N, Forget A, Shastri VP, Voelcker NH, Blencowe A. Antibacterial and anti-inflammatory $\mathrm{pH}$-responsive tannic acid-carboxylated agarose composite hydrogels for wound healing. ACS Appl Mater Interfaces. 2016;8:28511-21.

48. Hu D, Li H, Wang B, Ye Z, Lei W, Jia F, Jin Q, Ren KF, Ji J. Surface-adaptive gold nanoparticles with effective adherence and enhanced photothermal ablation of methicillin-resistant Staphylococcus aureus biofilm. ACS Nano. 2017;11:9330-9.

49. Irwansyah I, Li YQ, Shi W, Qi D, Leow WR, Tang MBY, Li S, Chen X. Grampositive antimicrobial activity of amino acid-based hydrogels. Adv Mater. 2015;27:648-54.

50. Zhang G, Yang Y, Shi J, Yao X, Chen W, Wei X, Zhang X, Chu PK. Near-infrared light II-assisted rapid biofilm elimination platform for bone implants at mild temperature. Biomaterials. 2021;269:120634.

51. Xiao Q, Mai B, Nie Y, Yuan C, Xiang M, Shi Z, Wu J, Leung W, Xu C, Yao S Wang $P, G a o L$. In vitro and in vivo demonstration of ultraefficient and broad-spectrum antibacterial agents for photodynamic antibacterial chemotherapy. ACS Appl Mater Interfaces. 2021;13:11588-96.

52. Zhang S, Hou J, Yuan Q, Xin P, Cheng H, Gu Z, Wu J. Arginine derivatives assist dopamine-hyaluronic acid hybrid hydrogels to have enhanced antioxidant activity for wound healing. Chem Eng J. 2020;392:123775.

53. Hu B, Gao M, Boakye-Yiadom KO, Ho W, Yu W, Xu X, Zhang XQ. An intrinsically bioactive hydrogel with on-demand drug release behaviors for diabetic wound healing. Bioact Mater. 2021;6:4592-606.

54. Krzyszczyk P, Schloss R, Palmer A, Berthiaume F. The role of macrophages in acute and chronic wound healing and interventions to promote prowound healing phenotypes. Front Physiol. 2018;9:419.

55. Zhao F, Zhao Y, Liu Y, Chang X, Chen C, Zhao Y. Cellular uptake, intracellular trafficking, and cytotoxicity of nanomaterials. Small. 2011;7:1322-37.

56. Zhao Z, Yan R, Yi X, Li J, Rao J, Guo Z, Yang Y, Li W, Li YQ, Chen C. Bacteriaactivated theranostic nanoprobes against methicillin-resistant Staphylococcus aureus infection. ACS Nano. 2017;11:4428-38.

57. Li YQ, Guan LY, Zhang HL, Chen J, Lin S, Ma ZY, Zhao YD. Distancedependent metal-enhanced quantum dots fluorescence analysis in solution by capillary electrophoresis and its application to DNA detection. Anal Chem. 2011;83:4103-9.

58. Li YQ, Zhu B, Li Y, Leow WR, Goh R, Ma B, Fong E, Tang M, Chen X. A synergistic capture strategy for enhanced detection and elimination of bacteria. Angew Chem Int Ed. 2014;53:5837-41.

\section{Publisher's Note}

Springer Nature remains neutral with regard to jurisdictional claims in published maps and institutional affiliations.

Ready to submit your research? Choose BMC and benefit from:

- fast, convenient online submission

- thorough peer review by experienced researchers in your field

- rapid publication on acceptance

- support for research data, including large and complex data types

- gold Open Access which fosters wider collaboration and increased citations

- maximum visibility for your research: over $100 \mathrm{M}$ website views per year

At BMC, research is always in progress.

Learn more biomedcentral.com/submissions 